\title{
WestVirginiaUniversity
}

THE RESEARCH REPOSITORY @ WVU

Graduate Theses, Dissertations, and Problem Reports

2015

\section{A Midsummer Night's Dream: A Transformative Process}

Jacob Bigelow

Follow this and additional works at: https://researchrepository.wvu.edu/etd

\section{Recommended Citation}

Bigelow, Jacob, "A Midsummer Night's Dream: A Transformative Process" (2015). Graduate Theses, Dissertations, and Problem Reports. 5208.

https://researchrepository.wvu.edu/etd/5208

This Thesis is protected by copyright and/or related rights. It has been brought to you by the The Research Repository @ WVU with permission from the rights-holder(s). You are free to use this Thesis in any way that is permitted by the copyright and related rights legislation that applies to your use. For other uses you must obtain permission from the rights-holder(s) directly, unless additional rights are indicated by a Creative Commons license in the record and/ or on the work itself. This Thesis has been accepted for inclusion in WVU Graduate Theses, Dissertations, and Problem Reports collection by an authorized administrator of The Research Repository @ WVU. For more information, please contact researchrepository@mail.wvu.edu. 


\title{
A Midsummer Night's Dream: A Transformative Process
}

\author{
By \\ Jacob Bigelow
}

Thesis submitted to the

College of Creative Arts

In partial fulfillment of the

requirements for the degree of

\section{Master of Fine Arts}

in

Theatre

Committee Members:

Robert Klingelhoefer (Chair), Associate Professor of Scene Design and Design Technology Program Director Steven Neuenschwander, Clinical Assistant Professor of Technical Direction and Production Manager Gerald McGonigle, Professor of Acting; Program Director, Graduate Acting

School of Theater and Dance

Morgantown, WV 2015

Keywords: Scenic Design, Technical Theater 


\begin{abstract}
This thesis document is a written account of my design process from start to finish for a production of $A$ Midsummer Night's Dream by William Shakespeare. This production was a product of West Virginia University; School of Theater \& Dance, and was presented in the Gladys G. Davis Theater in the Creative Arts Center in Morgantown, WV; the performances dates were November $19^{\text {th }}-21^{\text {st }}$ and December $2^{\text {nd }}-7^{\text {th }} 2014$. This document includes my analysis of the script, the steps of the design process, the execution of the design, and finally my analysis of the process.
\end{abstract}




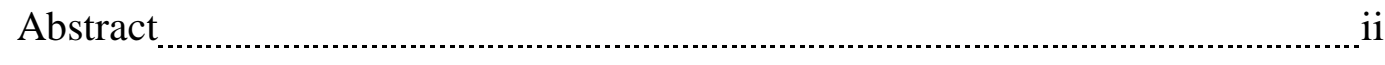

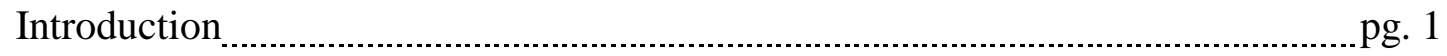

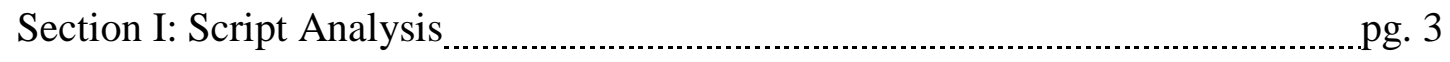

Section II: The Design Process

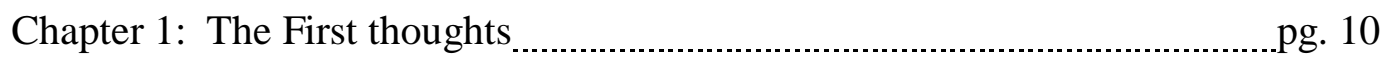

Chapter 2: Summer Talking ............................................................................pg. 11

Chapter 3: Down the Wayward Path ................................................................pg. 14

Chapter 4: Back to the Start 18

Section III: Design Implementation

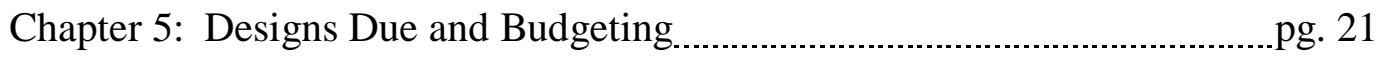

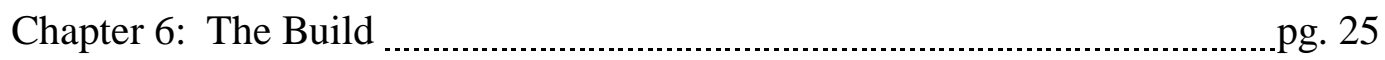

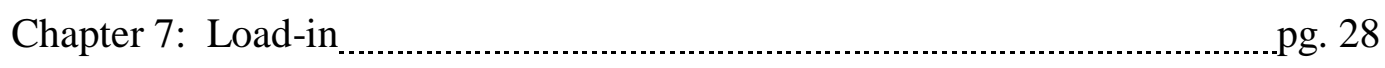

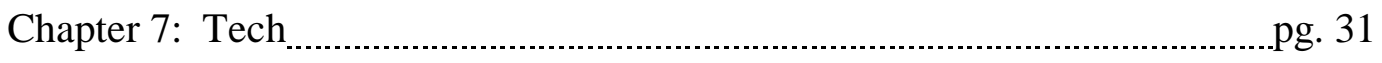

Section IV: Reflection

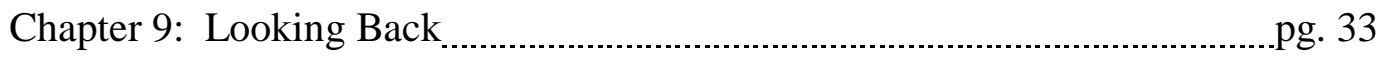

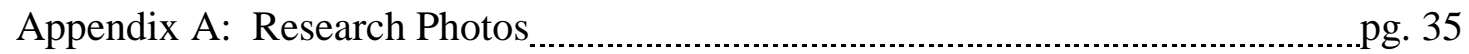

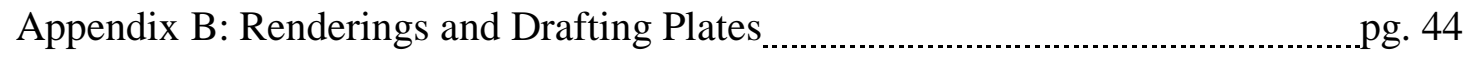

Appendix C: Production Photos

Bibliography: 


\section{Figures Table}

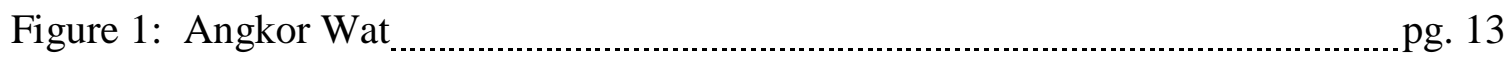

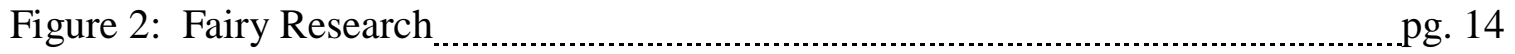

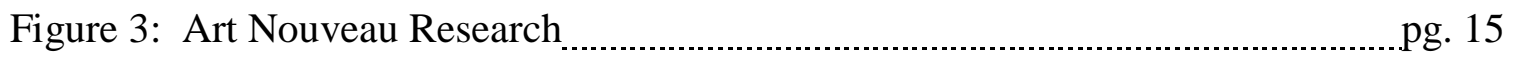

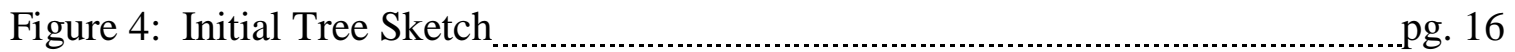

Figure 5: Human Nest Example

Figure 6: Photoshop Render 1 ...............................................................................pg. 17

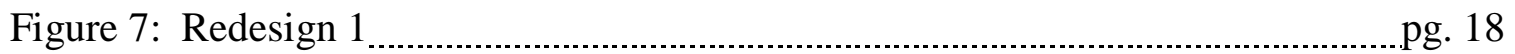

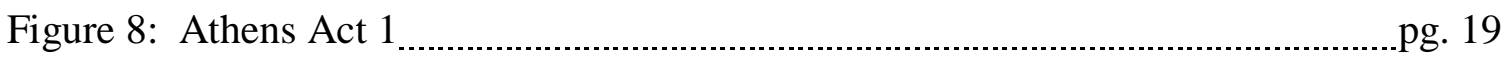

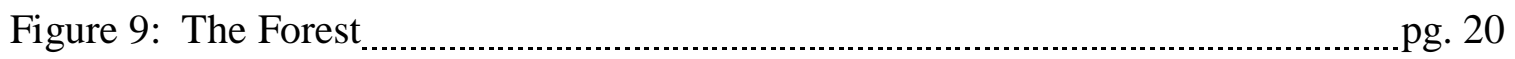

Figure 10: Grasping Tree Research _............................................................... 21

Figure 11: Redesign 2 Forest Render

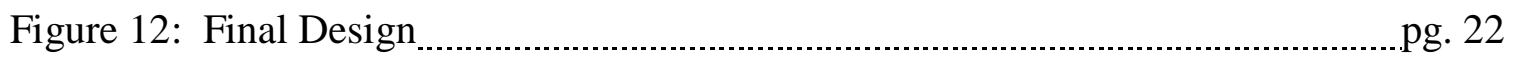

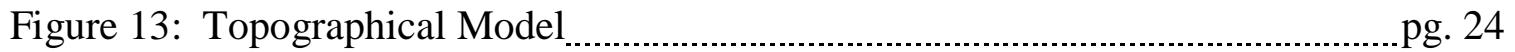

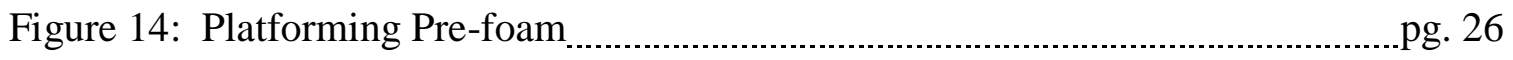

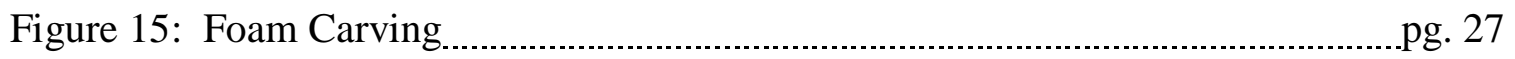

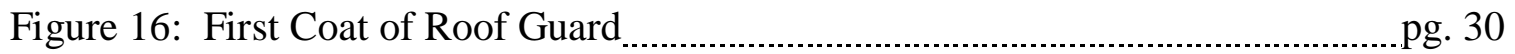

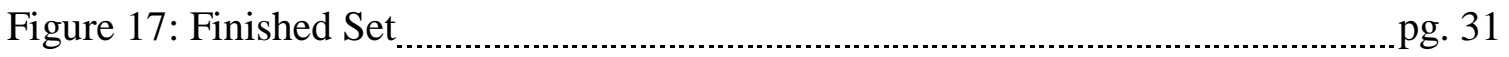




\section{$\underline{\text { Introduction }}$}

This thesis document is a written account of my design process from start to finish for a production of $A$ Midsummer Night's Dream by William Shakespeare. The artistic team for this show included the following: director Professor Gerald McGonigle; lighting designer MFA candidate Tim Thistelton; costume designer Professor Mary McClung; and sound designer Professor Alan McEwen. Our production team also included Michelle Kidd as the stage manager; Joe Dotts as the properties master; and Professor Steven Neuenschwander as Technical Director/Production Manager.

It is the job of the scenic designer to design the physical world that the actors will be interacting with throughout the course of the production. The scenic designer does so by interpreting the ideas in the script as well as the ideas and concepts that the director gives to them. Throughout the design process the scenic designer completes renderings, models, and drafted elevations that show the details of the world that they have created. This boils down even further in that the scenic designer is responsible for the overall aesthetic of the physical world. This includes any props or set dressings that are needed to complete their vision. The design process started on July $1^{\text {st }}, 2014$ with my first read through of the script and the designs where due on September $22^{\text {nd }}, 2014$. The show opened on November $19^{\text {th }}, 2014$.

This thesis is broken down in to four sections with each of the sections divided into individual chapters. In Section I: Script Analysis I will be taking a look at the ins and outs of the script. I will discuss the major themes that influenced my design choices as well as some of the undertones that are a pervasive force throughout the whole of the show. 
Section II: The Design Process, will provide an in-depth view of the whole of the design process. This will also include any obstacles or challenges that I had to overcome. I will peel back the layers of the design to show where some of the major decisions came from. In additions, this section will focus on the transformative path that modeled our final design. This section is broken down into four chapters as there were a lot of major changes that happened throughout the process, and because of this complexity we will be spending time dissecting the decisions that lead us to our final design.

In Section III: Design Implementation, we will be taking a look at the process of taking the design from the drawing board to a realized production. This section is broken down into four chapters and will be made up of initial discussions between Professor Neuenschwander, Professor McGonigle, Professor Klingelhoefer; my faculty advisor, and myself. In these chapters we will also be discussing the steps to create an organic structure on the stage, and the obstacles that had to be overcome throughout the process.

This thesis will conclude with Section IV: Reflections. In this section, I take some time to reflect back upon the whole of the design process. I will make comments on what I learned from this show; as well as reflecting back on things that I could have done better, and will strive to do better in the future. 


\section{$\underline{\text { Section I: Script Analysis }}$}

A Midsummer Night's Dream is considered a classic comedy by William Shakespeare, and at first glance it can look like a show that is filled with many simple themes. As in many of Shakespeare's plays, themes run a lot deeper then they seem at first. It was on the first read of the script that I started to see the depth of these themes. The script is littered with the ideas of love, lust, and a drive to seek love at all cost. Another theme that becomes more apparent with subsequent readings is one of transformation.

As I was reading I began to see an organic world that could lend itself to some really interesting action. While at first I was not sure what this meant as far as a physical structure, I knew that there was something primal that was being discussed in the text of the script. These primal urges are hinted at from the very onset of the script. In scene one the exchange between Hippolyta and Theseus, is wrought with the urges of a primal man. When Theseus says "Four happy days brining another moon - but $\mathrm{O}$, methinks how slow this old moon wanes! She lingers my desires" (Midsummer ${ }^{1}$. 1.1.3-4). He is talking from a more primitive version of himself; a version that longs for the touch of his queen, yet by the prescribed rules of society an urge that he must wait to fulfill.

These same desires are expressed again later in the same scene, but this time between the young lovers. This primal drive for love is first expressed by Hermia in her plea to Theseus:

${ }^{1}$ All quotes come from: Shakespeare, William. A Midsummer Night's Dream. Ed. Stanley Wells. Harmondsworth: Penguin, 1967. Print. 
I do entreat your grace to pardon me.

I know not what by what power I am made bold,

Nor how it may concern my modesty

In such a presence here to plead my thoughts;

(Midsummer. 1.1.58-61)

It is in proclamations like these that we start to see the ideas of the lust and the urge to act upon that lust become one of the main driving forces throughout the script. Again in this same scene we see the first plot driven by these urges start to unfold. In the closing of the scene Helena gives us a good look at what she is willing to do to obtain true love. She states in her monologue:

Things base and vile, holding no quantity, Love can transpose to form and dignity.

Love looks not with eyes, but with the mind, And therefore is winged cupid painted blind (Midsummer. 1.1.232-235)

Twelve lines after this proclamation of love she commits to set herself and Demetrius on a path of pursuit of Hermia and Lysander. It is this action in the pursuit of love that turns their world upside down as they enter the fairy world and are transformed by what transpires.

With the flight of one couple, and the ongoing pursuit of the second pair we change scenes where we are introduced to a new group of characters that with a light hearted silliness, will ease some of the tension of the previous scene. It is a device used throughout the show and in many ways gives us a desired break from all the tension that is built between young lovers. In this introductory scene we meet the quirky characters that make up the Mechanicals. We are 
also introduced to the idea that they are a company of players made up of handymen from around Athens. We find out that they are not particularly skilled in the art of performance, but they give it their all whenever they take the stage.

From the quirkiness of the Mechanicals, we move down a deep dark road into the forest, and into a world of fairy mystery and magic. It is with the introduction of fairies that we first see that we are no longer in the human world. The text's first interaction between Puck and a Fairy show us that we are now dealing with creatures of nature. The Fairy's response to Puck's simple question leads to the introduction of this world and its inhabitants:

Over hill, over dale, Through bush, through briar,

Over park, over pale, Through flood, through fire -

I do wander everywhere

Swifter than the moon's sphere,

And I serve the Fairy Queen,

(Midsummer. 2.1.2-9)

Puck's response to this reveals his identity as well as that of the one he serves:

The King doth keep his revels here tonight.

Take head for the Queen come not within his sight, For Oberon is pass fell and wrath

Because hath she has her attendant hath

A lovely boy stolen from an Indian king.

(Midsummer. 2.1.18-22) 
While these two converse we continue to find out more about the mischievous nature of Puck. Midway through their conversation there is an ill-timed meeting between Oberon and Titania; and it is from this that we get the feeling that there is something wrong with the natural world.

It is apparent by their first exchange that there is much wrong between the two. Oberon starts off with hostility in his first line "Ill met by moonlight, proud Titania!" (Midsummer. 2.1.60). In response Titania says "What, jealous Oberon? Fairy, skip hence. I have forsworn his bed and company" (Midsummer. 2.1.61-62). In many ways these conflicts were influential throughout the design process, and helped determine a few ideas about the design. As the first interactions between the king and the queen progress we get a glimpse of the major conflict that is about to transpire. In many ways there is a pettiness in the actions of Oberon and Titania that becomes more apparent as we progress in this act. It is these small petty actions that make Oberon and Titania seem human in nature. The play reads as if it is set in a place right at the cusp of the fairy with boundaries close enough that the humans can easily stumble into, and the fairies can sneak into the human world and create mischief.

It is in the next scene that the humans venture into the world of the fairies. Along with moving into the fairy world there is a level of humor that transpires between the lovers. It is the humor of love that has been taken to the extreme, and it is in extreme love that Helena has chased Demetrius into the forest to confess her love:

You draw me, you hard-hearted adamant!

But yet you draw not iron for my heart

Is true as steel. Leave you your power to draw, And I shall have no power to follow.

(Midsummer. 2.1.195-198) 
It is in this line that we see the depth of her love for Demetrius, and is a reflection upon the power that Demetrius holds over her. In return of her love Demetrius holds nothing but scorn and contempt:

Tempt not too much the hatred of my spirit;

For I am sick when I do look on thee.

(Midsummer. 2.1.211-212)

The interaction between the two young lovers acts as a catalyst for the folly that is to overtake them. As Oberon is left to bear witness to their interaction he contrives to have Puck anoint the eyes of Demetrius with a love potion.

Upon the exit of Oberon and Puck we are brought to the grove of Titania where she is singing a lullaby, and it is here that Oberon plays his first piece of mischief on her. As he places the love potion in her eyes he expresses:

What thou seest when thou dost wake,

Do it for thy true love take;

Love and languish for his sake.

Be it ounce or cat or bear,

Pard, or boar with bristled hair

In thy eye that shall appear

When thou wakest, it is thy dear...

(Midsummer. 2.2.33-39)

Hermia and Lysander enter and there is a closeness to their love that makes it hard for them to resist the physical urges that comes from new love. The urge for intimacy is expressed best by Lysander when he says: 
One turf shall serve as pillow for us both;

One heart, one bed, two bosoms, and one truth.

(Midsummer. 2.2.47-48)

In response to Lysander's forward statement Hermia says:

Nay, good Lysander, for my sake, my dear,

Lie further off yet; do not lie so near.

(Midsummer. 2.2.49-50)

It is this action that leads Puck to believe that these are the two Athenians he has been sent to search out. The magic of the herb is so powerful that it can break the love of a man for one woman, and make him fall in love with another, and that is exactly what happens when Helena stumbles upon Lysander asleep on the ground. In the act of waking Lysander, Helena inadvertently makes him fall in love with her, and forget his love for Hermia. Lysander expresses his change of feelings when he says:

Content with Hermia? No I do repent

The tedious minutes I have with her spent

Not Hermia but Helena I love.

(Midsummer. 2.2.117-119)

His expression of love shows the nature of the potion that both Puck and Oberon have at their disposal. Helena's response to Lysander is one of shock as from her point of view Lysander does nothing but treat her with scorn and distain:

Wherefore was I to this keen mockery born?

When at your hands did I deserve this scorn? 
Is't not enough, is't not enough young man

That I did never - no, nor never can-

Deserve a sweet look from Demetrius' eye

But you must flout my insufficiency?

(Midsummer. 2.2.129-134)

As the lovers exit we find ourselves back in the company of the Mechanicals. Act three starts with them stumbling upon Titania in the grove that she is using as her resting place. As they rehearse the piece that they wish to perform for Theseus on his wedding night, Puck enters as their rehearsal is in progress saying:

What hempen homespuns have we swaggering here

So near the cradle of the Fairy Queen?

What a play toward? I'll be an auditor-

An actor too, perhaps, if I see cause.

(Midsummer. 3.1.70-73)

When Bottom makes his exit from the stage Puck seizes this moment to turn him into an ass and thus scare away Bottom's companions. The ruckus caused by the Mechanicals as they leave awakens Titania to discover Bottom waiting for his friends to return. Upon laying eyes on Bottom she falls deep in love with a man with an ass head adhered to his own.

Act III Scene II starts off with Oberon finding out that his Queen has fallen in love with a monster. Puck states:

My mistress with a monster is in love.

Near to her close and consecrated bower,

While she was in her dull and sleeping hour,

A crew of patches, run mechanicals 
That work for bread up Athenian stalls, Were met together to rehearse a play...

(Midsummer 3.2.7-12)

In reply Oberon responds:

This falls out better than I could devise!

But has though yet latched the Athenian's eyes

With the love juice, as I did bid thee do?

(Midsummer 3.2.35-37)

Puck responds in the affirmative, but the folly of Oberon's mischievous side kick is soon revealed. As Demetrius and Hermia argue it becomes evident that Puck has placed the love potion on the eyes of the wrong Athenian. Oberon's remedy for this is to use a love potion on Demetrius and Puck is sent in search of the antidote. Yet before Puck leaves Lysander and Helena enter and they do not spot Demetrius who is asleep not far from them. As they argue the noise wakes Demetrius who, under the effects of the potions, is stricken with love for Helena. The love that both Demetrius and Lysander feel for Helena leads them to duel each other, and at the same time Lysander's change drives Hermia to fight Helena.

We see yet another human trait from Oberon when he sends Puck after the men to stop them from killing one another. Puck leads the young lovers around in a merry chase until they fall to the ground in exhaustion and fall asleep. Not long after the young lovers have fallen asleep Titania and Bottom enter looking for a flower bed in which to spend the day sleeping. As day starts to creep over the land Oberon wakes Titania from her sleep to take her away from the monster she was in love with. With the King and the Queen of the forest retreating into the dark 
depths of their realm we are brought back to the human world by the entrance of Theseus, Hippolyta, and Egeus who are hunting for game in the forest.

They stumble upon the young lovers who are asleep in the forest. Hermia and Lysander who have run away in the name of love, and to avoid the enforcement of the will of Egeus. Demetrius who followed the two lover in hopes of finding them and waylaying them in their effort to undermine his will. Helena followed Demetrius because of love and many ways received more than she bargained for. If not for the fairy magic that Oberon and Puck used they would have had a very different story to tell. With a resolution to who is going to marry whom we move onto the final scene of the show.

We return to Athens as the court is about to enjoy some entertainment in celebration of the weddings that just took place. With the Mechanical's performance of "Pyramus and his love Thisbe" the show comes to an end on a note of love and mirth. In many ways this show is about the love and the lust of man, but also the power of nature, and how there is a strange seduction for man in nature. 


\section{$\underline{\text { Section II: Design Process - Chapter 1: First Thoughts }}$}

After my first read through of the script I started my first round of image research, and while doing so I spent some time jotting down some of the ideas that had surfaced as I was reading. It was these ideas that would later become my scenic breakdown; describing each of the scenes in detail. At this point the ideas were a vague shadow of what they would become, but I knew that the driving force in the script was one of change. Not necessarily a need for physical change, but a transformation of rules in society. The fairies are the physical embodiment of the transformative power that nature can have on man. It also seemed that there was a lustfulness to the show, and it is shown in the sensual words and action of the lovers.

One of the things that really stuck out to me was the idea of there being one major element that represented the land of the fairies. It could be something that would possibly interact with the bower, but did not need to be the bower. I did not see a need to have the set change every time we changed location; as there is a flow to the script that needs to be maintained. The cadence of the show could have been easily broken if there were too many unnecessary scene changes. There is an elegance and seductive nature to revealing elements that are hidden within the design, and this became something that early on in the process filled my thoughts.

The seductive nature of the revealing of hidden elements was also driven by the idea that the fairies where a part of the natural world. It was their oneness with nature that made them seem alien to the humans, but it was their human like interactions with one another that gave them a seductive quality that could enhance the world if done correctly. As I thought about these ideas more and more I started to see their world as something organic. Something that, as they interacted with the space, separated them from the humans who stumbled into their world. 
With these ideas firmly in place I started my image research to see what I could find that might mimic the elegance and seduction found in nature. I was initially drawn to images of nature that had reclaimed lands thought tamed by man. I intentionally kept my first round of

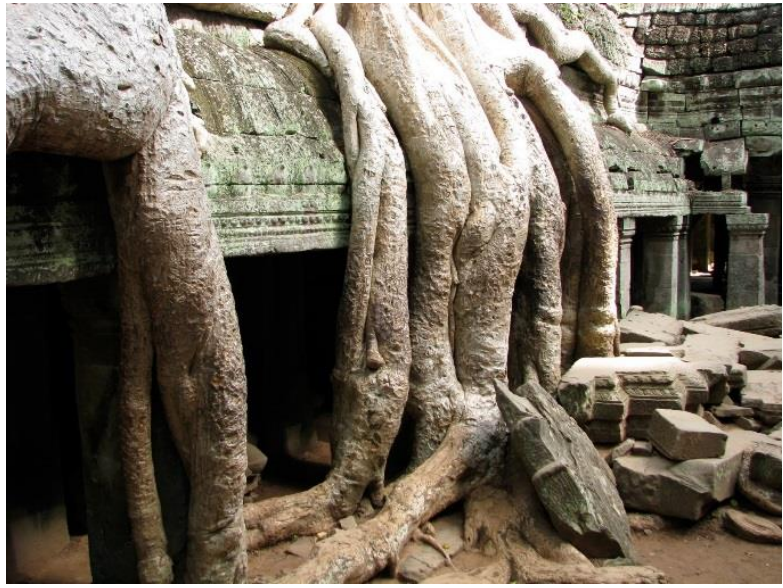

Figure 1: Angkor Wat research small because I had yet to have a conversation with Professor McGonigle about the direction that he would like to take the show. During my initial round of research I found the picture shown in Figure 1: Angkor Wat, and it struck me as a world that I could see the fairies living in. It was not long after I had finished my first read through, and had started my initial research when I received an email from Professor McClung that started a conversation about the show with the rest of the artistic team. 


\section{Section II: Design Process: Chapter 2 Summer Talking}

It was this email that spawned the initial conversation between Professor McGonigle and me, and from there we set up a time to have a phone conversation and discus the show. Our initial conversation was more over the ideas that were contained within the show; as well as the overarching themes that pertained to the physical world. We also discussed the initial idea of how some sets of characters might interact with the world that we would create.

In our conversation Professor McGonigle had brought up an idea that had been bouncing around in my head since I had finished my first read through. That idea was that this show is in many ways about the urges of love making, but not the act of making love. At this point, he sent

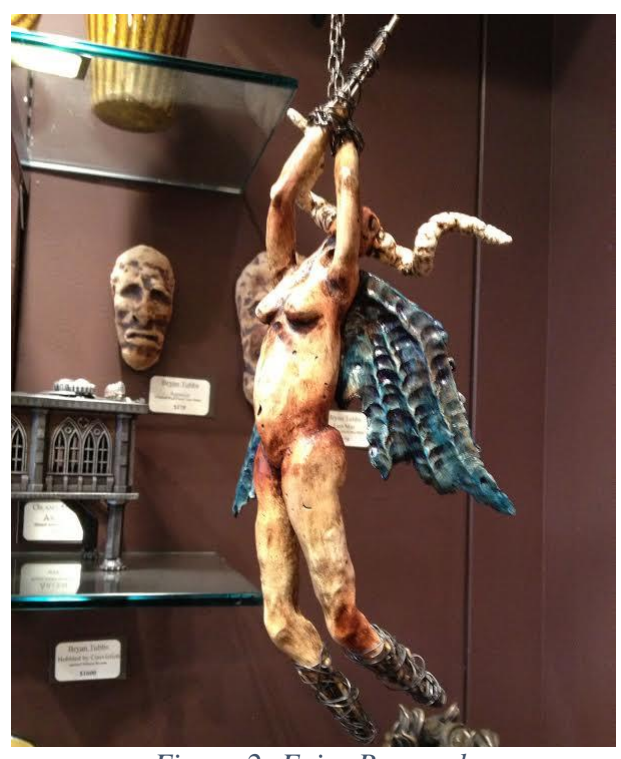

Figure 2: Fairy Research me an email with images that embodied his idea of the fairies.

Figure 2: Fairy Research is one of the images that he sent. His idea for the fairies was that they embodied something that is part nature, but also had a human sensuality. He wanted to create the idea that they were creatures that had a sexual and sensual nature, but at the same time strange and other worldly.

The ideas for the fairies were great insight for how Professor McGonigle saw the interplay between them and the set. We talked briefly about the physical space he envisioned,

and one of the ideas that we explored from the beginning was that the bower should be the center piece; or rather that there should be a center piece that was from the world of the fairies. We also discussed the idea that this unit should also house the bower. 
After our initial conversation I turned my attention back to the script to see what other hints might lie within its pages. At this same time I was working on my scene by scene break down, and I started to take note of some of the details that I found. Some of the items that I took note of were: Athens Scene One, I would like a look that captured the rigid lines and formal feeling found in a traditional colonnade; also that we might need multiple looks while in the forest; and finally that I wanted a look for when we return to Athens that was loser and more celebratory in nature. Other than these few concerns I did not see much that could not be accomplished with some prop pieces and small set dressings.

It was at this point that my focus for my research became the idea of blending the human world and the fairy world. I started looking into the Art Nouveau movement because it blended the styles classical architecture and the curvilinear line of nature. It was this blending that drew me

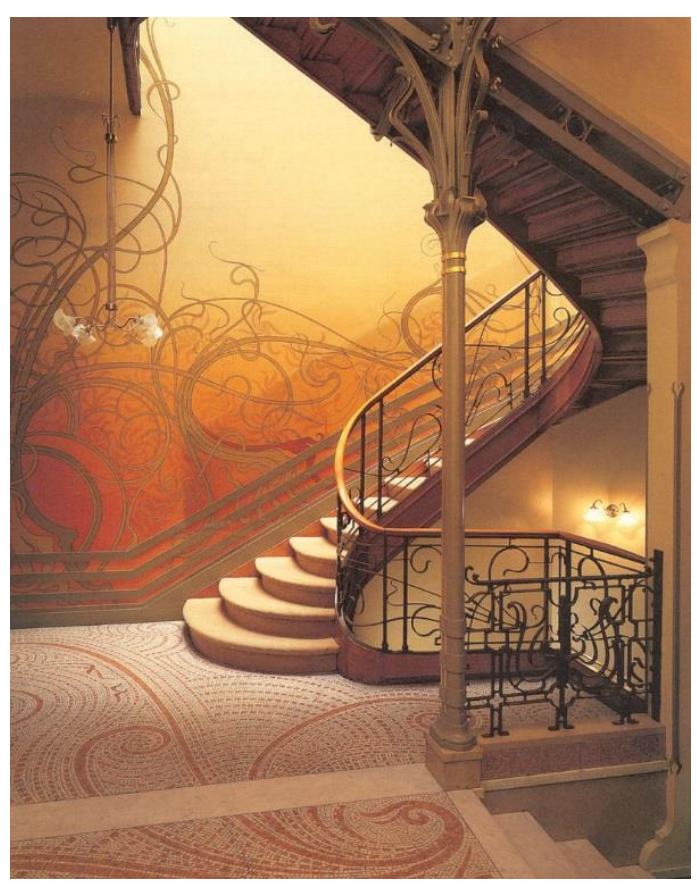

Figure 3: Art Nouveau Research to it as the idea that was forming in my mind was to have a blending of the two worlds. The image above is a prime example of the use of the Art Nouveau movement; especially its use in architecture. As I continued Art Nouveau research, I began to see the fairy world as a single tree that could represent the forest as a whole. I initially saw this tree residing on a platform, and with the image of Figure 1: Angkor Wat filling my thoughts I started to sketch out some ideas. These two ideas began to blend the sensual curves of Art Nouveau into the human world, while the rigid structure of the tree in the fairy world could act as an anchor for the world of the play. 
In this initial round of research I also took a look at prints from the Art Nouveau

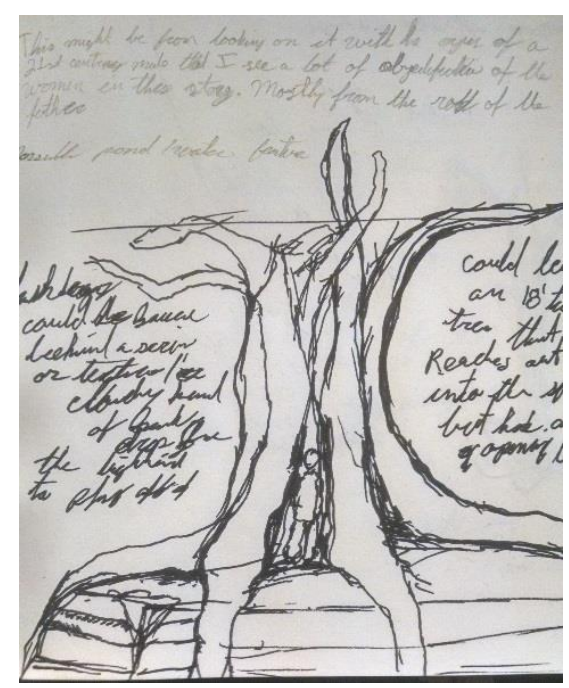

Figure 4: Initial Tree Sketch

movement and found some really interesting images that helped start a conversation between Professor McGonigle and myself about how the fairies would interact with the space. As we progressed towards the end of the summer, and our initial design meeting with whole team, I was really interested in the idea of having a tree that had the bower inside of it. I sketched out towers that blended into the natural world when in the forest, and became columns while in Athens. The image to the left is one of the initial sketches of the tree, and how it could branch out into the space.

It was at this point that we had returned from our summer vacation, and we had our first design meeting with the whole design team. While at this first meeting we talked briefly about the show itself, and what it represents to each of us. It was in this meeting where we started to veer away from the idea of the literal tree, and toward something that was more of a metaphorical representation of a forest. In our conversations at this time we talked a lot about the idea of the forest having a "wet" feeling to it; as well as the space having a sensuality driven by nature. This meeting laid the initial ground work for the world that we wanted to create. We knew that the world needed to have three distinct looks: one for Athens at the top of the show; one for the forest; and one Athens at the end of the show. 


\section{Section II Design Process: Chapter 3: Down the Wayward Path}

Not long after we wrapped up our first meeting where we discussed the world that we wanted to create that my ideas started to diverge from their original path. I met briefly with Professor Klingelhoefer a few days after our initial design meeting and we chatted about how having a naturalistic tree design was going to be expensive, and how it would most likely be over budget and hard to cut to get back on budget. It was on his advice that I sat down with Professor McGonigle to discuss the set, and it was then that we started talking about a metaphorical forest. We talked about the abstract ideas for the parts of the forest, and that the actors had to be able to interact with them in natural ways, but we were uncertain of what the abstracted metaphor for the forest might look like.

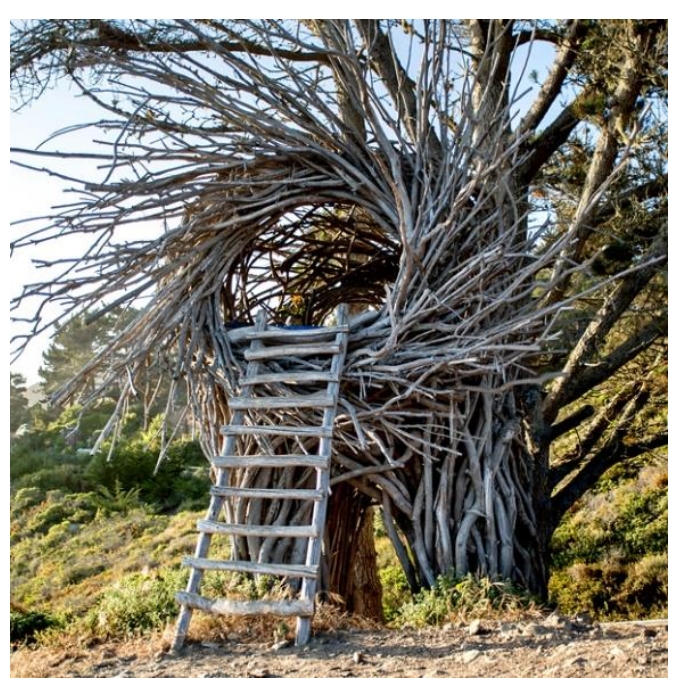

Figure 5: Human Nest Example a nest of sorts came into being, and the idea that the trees in the forest could be represented by

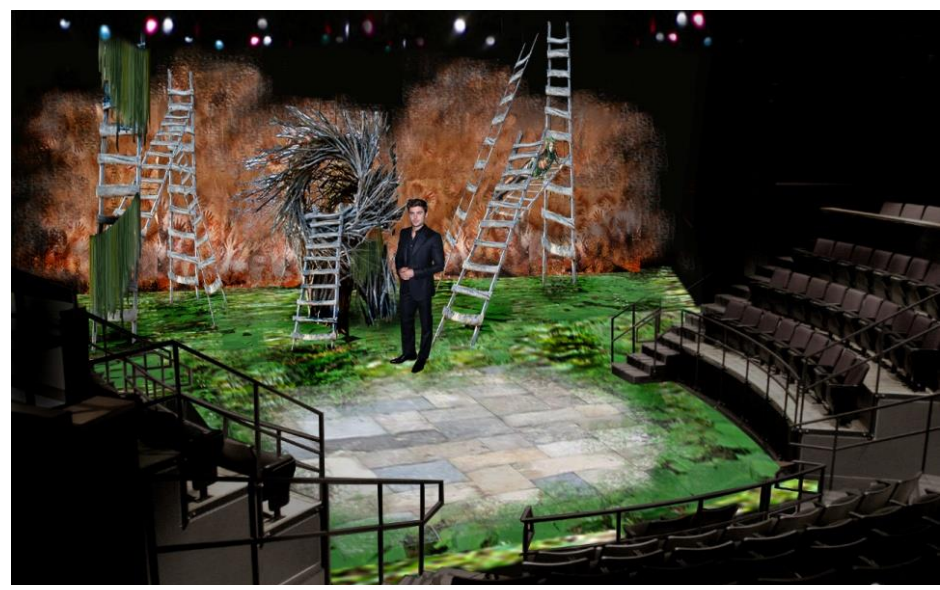

Figure 6: Photoshop Render 1 ladders. I began doing research into what a human nest might look like, and as I dug into the research I found some very provocative images. Figure 5: Human Nest Example is one of many nests that I found while researching them. It was with these images and a vague idea of what an abstracted forest might look like that I started to put my first

Photoshop rendering together. Figure 6 is the completed render. 
It was this image that got us really talking about how the actors might really interact with the space. Throughout our conversations we had discussed the idea that the fairies would be a natural part of the forest, but when the humans entered the forest they would feel out of place and would have a hard time moving around in the forest. Around this time Professor McClung found a wonderful piece of research that gave us the first real glimpse of what the fairies might become. This piece was a video called the Natural Fashions of the Omo Valley, Ethiopia, and this video showed how the tribes of the Omo Valley used items in nature as garments blending and often blurring the line between man and nature. There was a strangeness to the individuals in this piece that made us wonder what if the fairies looked like they wore materials that came from the set. What if they looked like they had come directly from the earth?

From this point forward we dug deeper into a realm of something that was even more metaphoric in nature. After looking at the first rendering that I produced Professor McGonigle and I sat down and decided that it was not the right metaphor for the show. We reworked the

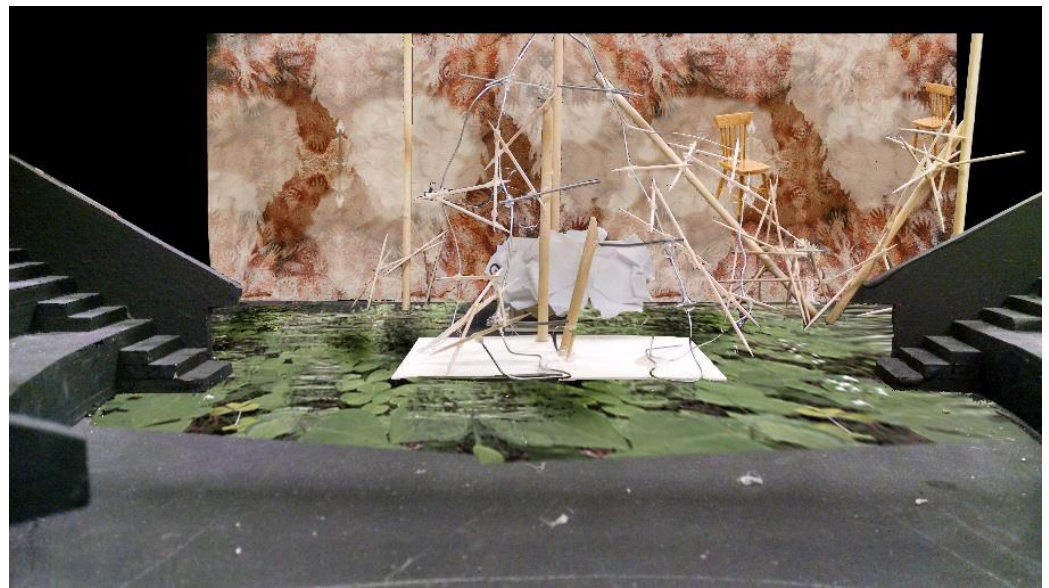

Figure 7: Redesign 1

initial metaphor because the worlds felt too separate. It was hard to see how the world of the humans and the world of the fairies interacted with one another. Roughly a week after the first rendering Professor McGonigle and I took a look at the redesign of the set that transpired, and it was at this time that we took a very major turn into something that looked more reminiscent a Brechtian version of Midsummer. Figure 7: Redesign 1 above was a rough model with some Photoshop elements to give us an idea of the set. Professor McGonigle and I met and 
we talked over the model and rough sketch; at the time he seemed to get excited about the concept, but was hesitant because at this point it was a very rough concept. He wanted to see a more refined version of the concept; something that was more fleshed out and had a bit of magic to it.

This meeting took place on September 3, and over the weekend I worked to flesh out the model and create a more refined rendering. We began to see some of the ideas that made it into the final design starting to emerge. Figure 8 primarily pertains to the look of Athens in act one, and the idea of that scene is distinguished by the use of fabric

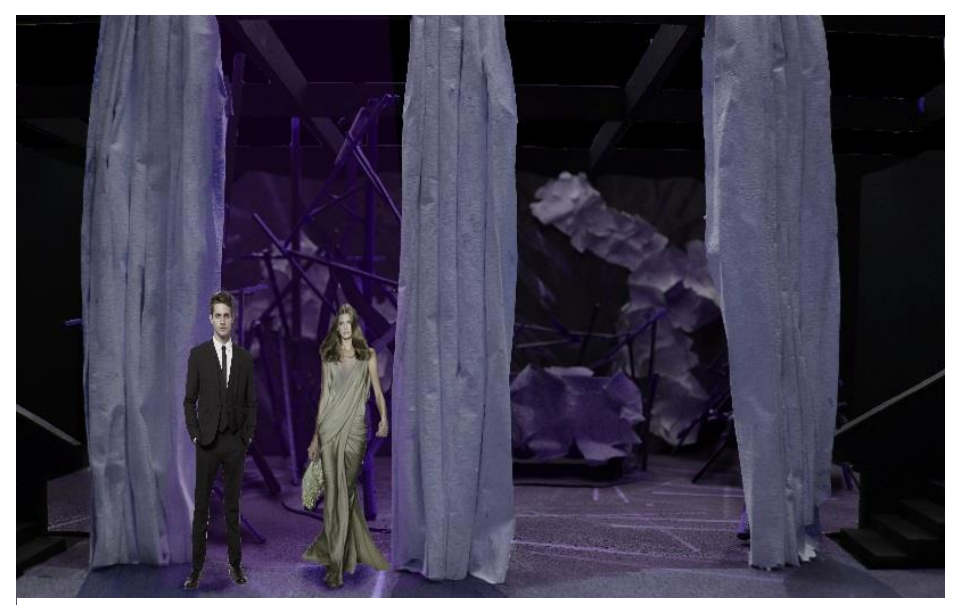

Figure 8: Athens Act 1 panels that were cut to look like columns. It was this rendering that I showed Professor McGonigle four days later. From this point forward we worked to refine this ideas into something that was workable, and we also started exploring the idea of transformation. The transformation is something that happens throughout the script, and was something Professor McGonigle brought up. He said that the show has a transformative nature to it, and that the characters start off in this world of frustration, and sexual tension, and that as the night progresses and we move deeper and deeper into these feelings. Then by the time we hit the morning we are starting to see the world brighten, and finally when we return to Athens we feel like the formal rigidness has given way to something more relaxed

While we started to see some of the final ideas appearing in this redesign there was still something missing, and it is from here that we took another leap. This time we moved away 


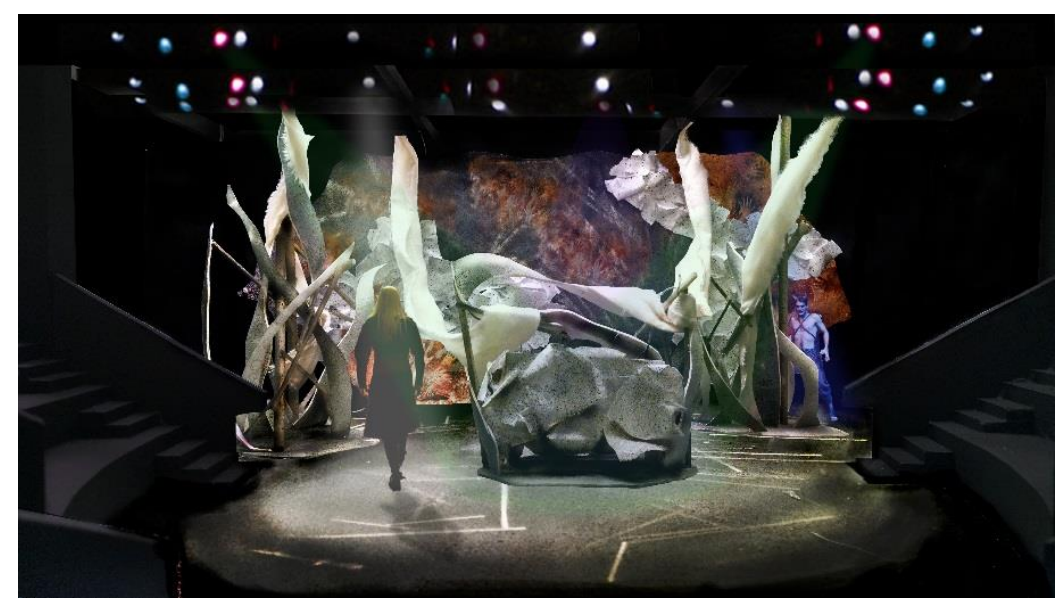

Figure 9: The Forest from the Brechtian look and moved into something that was more a combination of pieces. Figure 9 shows the evolution of the design to this point. It was this step in the evolution that took us to the edge, and was something that both Professor McGonigle and I were excited about. There was still

the feeling that something was missing in the design. Professor McGonigle started to step through the action of the show, and in conversations with him it seemed like he was having a hard time making the set work for the actions he saw taking place in the show.

Professor McClung suggested that we should meet as a full group at this time as she was also struggling to find a connection between the design of the costumes; and how they fit in to the world the set was creating. We planned to meet on the $15^{\text {th }}$ of September to take a look at each other's work to see what could be done to make sure the designs meshed. In many ways it was not what transpired during the meeting that was formative to the design, but what transpired afterwards that lead us to the final design. 


\section{$\underline{\text { Section II Design Process: Chapter 4: Back to the Start }}$}

With the deadline for final designs looming we decided that a redesign of the set was needed. It was difficult to accept, but I knew deep down that the design progression that we

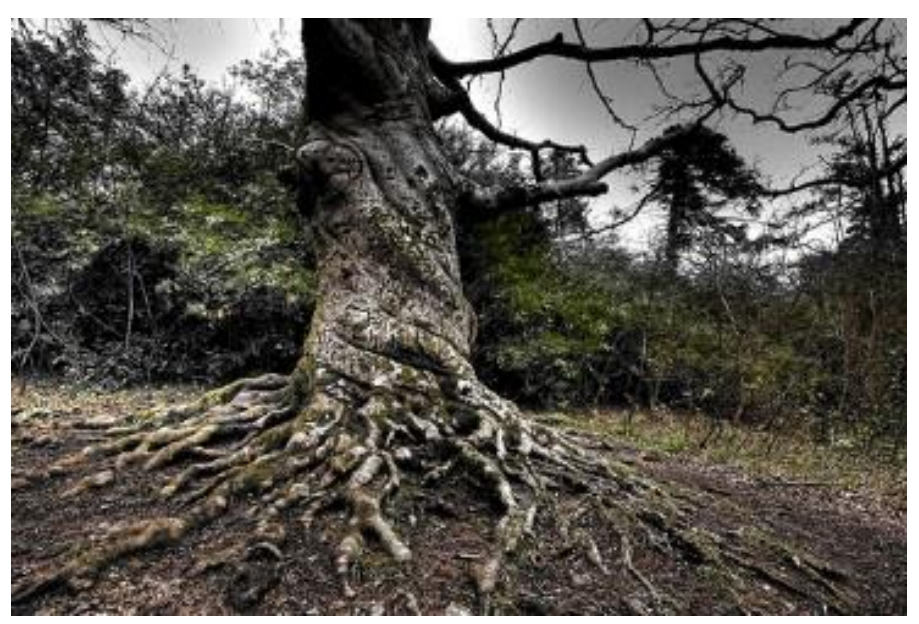

Figure 10: Grasping Tree Research went through was something that we needed to do to explore. Throughout the whole of the design process there was a research image that I had pulled very early on that spoke to Professor McGonigle. It was the primal nature of Figure 10 that became one of, if not, the most important image in all the research.

After the meeting to look at the progress everyone had made Professor McGonigle, Professor Klingelhoefer, Tim, and I stayed in the design room looking at the model and talking about the show. Professor Klingelhoefer asked a series of questions that lead to the discovery that changed the whole design. Frist Professor Klingelhoefer asked Professor McGonigle what it was he needed to make the show work. Professor McGonigle's answer was that while really he could do the show with a bare stage. The question was then asked of Tim if he could light the show with nothing, but a bare stage. Tim answered that he could, but it would not be a very interesting show. Then finally the question was asked of Professor McGonigle what do you want to have for a set? It was from this question that I was able to get most of the information to make the first version of the new design.

I managed to turn out a new model and rendering the next day, so that we could take a look at it and make any revisions that would be needed before final designs where due. I felt like many of the ideas that I had at the beginning of the process begin to click into place. The world 
started to become something

that I could see the fairies that

Professor McClung was

creating could live in, and in

many ways the world started

to become somewhat of a

barrier to the humans as they

would try to move around the

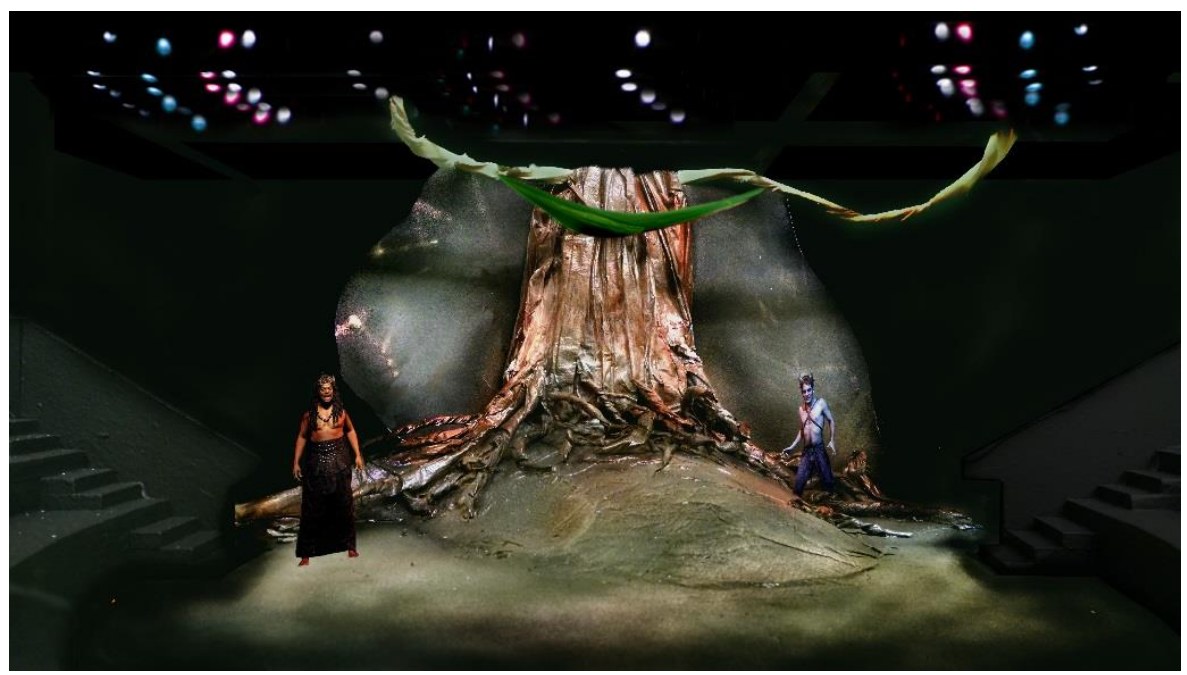

Figure 11: Redesign2 Forest Render

set. It was from Figure 11 above that we started to really work out some of the issues we saw.

I think the first issue that Professor McGonigle raised was the idea of the bower. The idea that I proposed was that the bower would be a flying unit; something along the lines of hammock. I wanted it to be something that could envelope Titania, yet I had some concerns about the strength of a hammock, and if would flex too much when it was being raised and lowered from the grid. One piece that Professor McGonigle wanted to add to the set was a downstage platform, and with addition of this one last platform that we started to see the outline

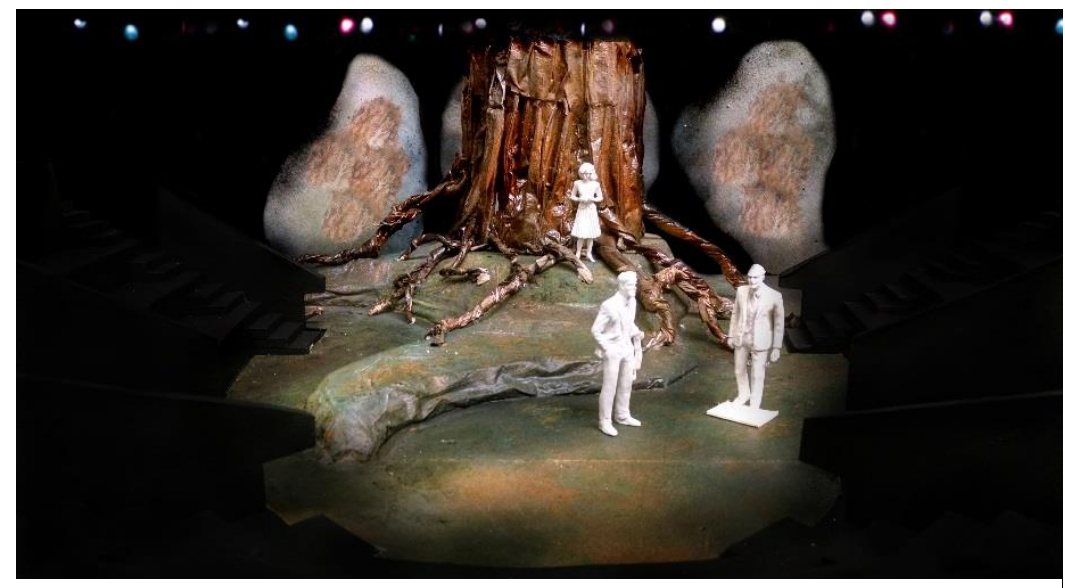

Figure 12:Final Design of what would become the final shape of the set.

Then I worked out the last few details pertaining to the platform sections, and rebuilt the model one last time; Figure 12 shows the model in its completed state. Even with all its trials and tribulations throughout the design process the final product was worth all the waiting. Through the process 
we traveled from the idea of the large singular tree, and down into the reaches of a Brechtian forest made up of pieces that moved and were completely climbable. Only to return to the idea of a large tree that would create a world that encompassed the transformative ideas that riddled the pages of the script. A world that would have a complicated build, would stretch the shop, and let us explore some new products for some old tricks. I was excited to push forward and see the naturalistic world that we had come back to come to life. 


\section{$\underline{\text { Section III Design Implementation: Chapter 5: Designs Due }}$}

As with most shows there is a time when all the designs are due and the budgeting process must begin. It was with this date in mind that the last redesign took place and was completed. Our final designs were due on September 22, 2014, and it was at this time that we presented our final design ideas to Professor McGonigle and the rest of the artistic team. After the design presentations where completed Professor Neuenschwander, Wyatt Corbin; our Assistant Technical Director, and I sat down to take an initial look at the design drawings. With the redesign of the set happening so late into the process I was unable to complete drafts to the level of detail required for this set, but after our initial discussion we came up with a plan of attack to get them the details needed to budget the show.

Our plan of attack was that I would build a topographical model of the hill platforming so that we could get a better idea of what the contours would be. I would also revise some of the drafts to give more detail; and send them a rendering and the AutoCAD file to start budgeting from.

After the meeting I went to the design studio where I was able to produce the topographical model in short order. Figure 13 on the right is what the topographical model looked like, and with this piece Professor Neuenschwander and Wyatt where

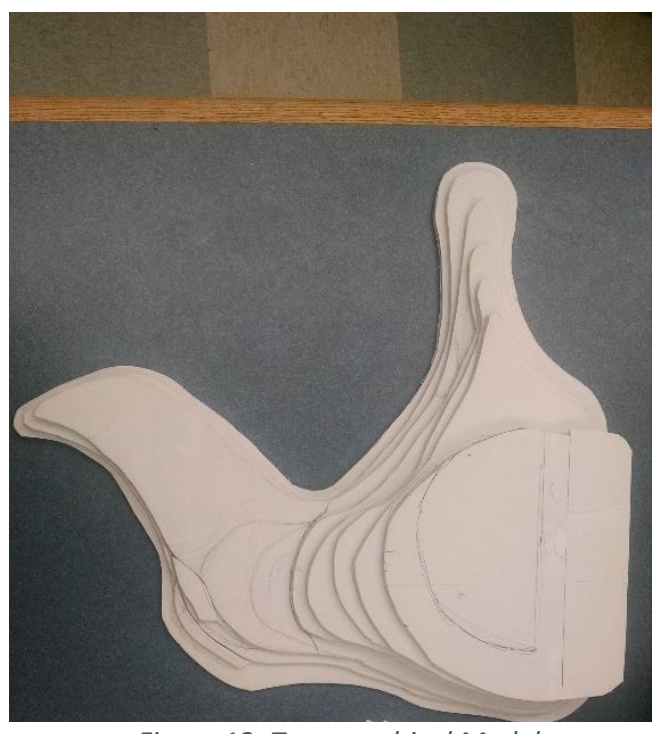

Figure 13: Topographical Model able to get an idea for the contour of the platforming as well as how the tree was positioned.

On Sunday of that week I received an email from Professor Neuenschwander asking a couple of questions pertaining to the set. These questions ranged from what were the budgetary needs for paint, and items more specific. One of items he need more specific details on was the 
location of the opening in the tree for the fairies to climb out. On Monday I stopped into his office to chat over the questions that he had as some of them were easier to answer with us looking at the drafting. Professor Neuenschwander wanted to have the budgeting wrapped up on Wednesday October 1, 2014 so that they could move on to the next step in the process, but as the final budgets came in we found out that we were roughly $\$ 2,200$ over budget and needed to make some cuts to the set.

While I had some idea that we where most likely going to be over budget; becaue of the organic nature of the set, I did not believe that we would be so far over budget, and with being over budget Professor Neuenschwander, Professor McGonigle, Professor Klingelhoefer, and I needed to sit down and discuss what needed to be changed with the design. We decided to sit down on the Friday of that week to discuss the draftings and anything that we thought might be able to be changed to help us lower our budget numbers. At this meeting Professor McGongile brought up the fact that this show was going to be used for our National Association of Schools of Theater reacrreditation, and that we might be able to get some extra capital from Professor Joshua Williamson, the director of the School.

A few days after our meeting I was informed that we were given the extra capital that we needed to produce the design as long as we added a number of peformances for local area schools. After all was said and done we received an extra $\$ 2,000$ to our budget, and we added the required performance. As a result, the money allowed us to produce the set, and we were able to move forward into the next phase and build the show. 


\section{Section III Design Implementation: Chapter 6: The Build}

With the budget estimate complete we were able to start the build process for the show, and I knew going into that this was going to be a fairly involved process for me. Part of the reason was due to all the carving that would need to be done, and the other part was because I know that my drafting was missing key details for parts of the platforming. I would have to be around to make decisions about parts of the set. The way the build broke down was that the crew built the major sections of the platforms, and then I would step in and help complete the look of the set by filling in any sections of the deck that needed to be filled in. As far as the tree, I did not get involved in this part of the project until later on in the process. The crew built the platform rings that made up the top, middle and bottom of the tree, and then as they added the $2 \times 8$ 's that acted as the vertical supports for the tree, I came in and drew the profile.

At this point I stepped out of the shop for a while to help Wyatt come up with a plan of attack for the surround of the hill platforms, and how we were going to deal with the center ramp platform. As this was his first time being an assistant technical director I helped give him some guidance on some of the more difficult sections of platforming. It was at this point the major section of the platform had been set up in the upper

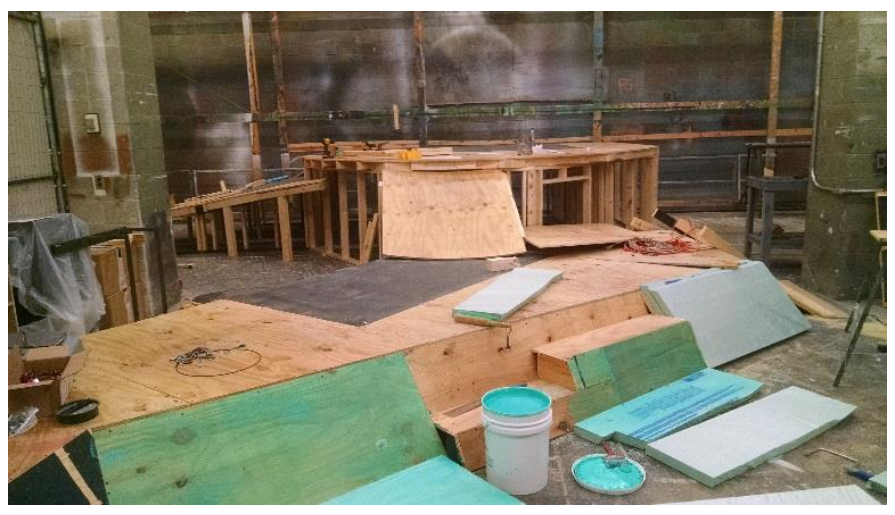

Figure 14: Platforming Pre-foam

shop. We were able to start setting the side sections and get them prepared for the foam treatment that would allow us to carve them into a more organic structure. Figure 14 shows what the platforming looked like before we started to apply the foam. It was at this point that Professor Neuenschwander decided that we needed to have a few extra work calls in order to get 
the set into the space on time. At these work calls we were able to get a lot completed and get ourselves back on schedule.

These work calls were filled with the application of the foam and finishing fleshing out all the sections that needed pieces added. At this point in time the skeleton of the tree was complete and we planned on finishing the tree in the space due to the physical limitations of the load door; to the Davis Theater. The process of attaching the foam to the underlying structure is something that takes time. The contact cement that we used for this process is called $3 \mathrm{M}$ Fastbond, and it can take anywhere from fifteen minutes to a half hour to be cured enough to adhere. We applied a double layer of foam to most of the surround, and as we worked through each section we found the trouble spots and addressed them as needed.

After we had gotten most of the foam layers attached I switched over to starting the process of carving the foam leaving a crew with instructions to finish attaching foam in specific

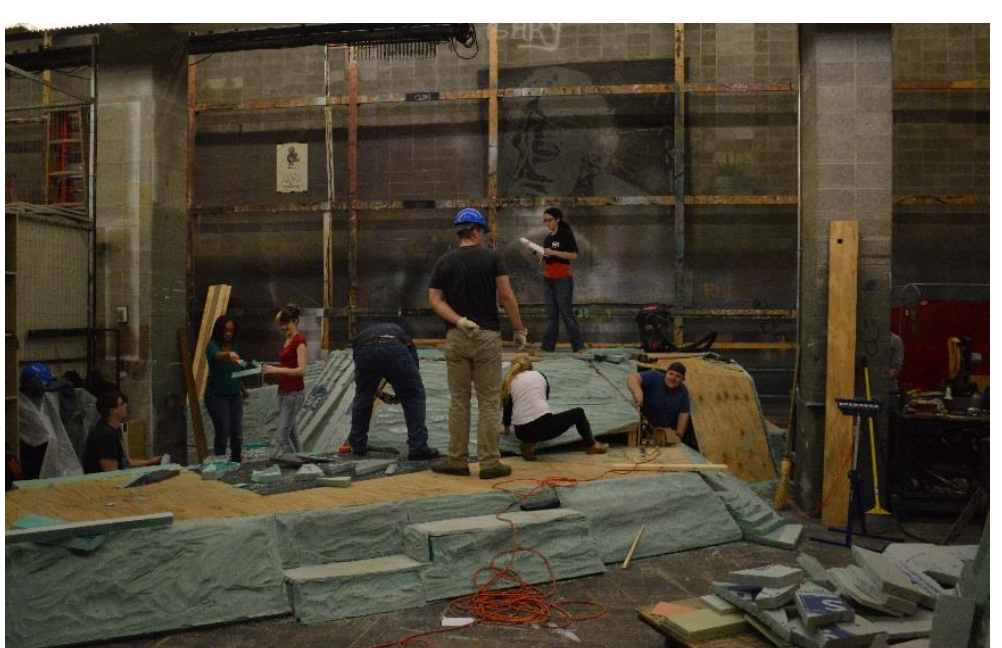

Figure 15 Foam Carving areas. I started off the carving process with various hand tools these included rasps, various hand saws, and knives. It was slow going as I was still trying to formulate exactly what I wanted to get out of the foam, and it was at one of these work calls where Joe Dotts; who was helping do some of the carving; suggest that we use angle grinder to help remove a lot of

material, and get closer to the texture we were looking for. Figure 15 shows the texture look that we were able to achieve in this process. As we worked through process of applying foam and carving it there were only a few flat sections that I decided to attach foam to. These sections 
where toward the tip of the stage right ramp, and we did this help hide the transition from the platform to the stage floor. We managed to wrap up the carving right as we needed to move into the space. 


\section{$\underline{\text { Section III Design Implementation: Chapter } 7 \text { Load-in }}$}

The crew moved the set into the space in fairly short order as all the sections of set were designed in a way to be taken apart, and be reassembled. With the reassembly of the platforms we were able to move on to the next piece which was the tree. The base of the tree went up on the platform fairly easily, but the crew struggled a little bit with the top. After a little bit of planning we managed to lift it into place. While I moved onto another project, the crew attached

the ribs. At the same time that the tree ribs were getting installed; I lead a crew on finishing up the foam sections and getting them prepared to be covered in their hardening agent. In order to prepare for the elastomeric coating we covered some areas of the platform in light weight muslin in order to give those sections a more uniform look, and in other sections we filled cracks with Great Stuff expanding foam.

With all the prep work complete I finished some small carving on the expanding foam before we could apply any layers of the elastomeric coating to harden the foam and make it a walkable surface. At the same time as we applied the first coat of elastomeric coating we finished the texture of the tree. The texture of the tree was created by using an under layer of chicken wire that we stapled to the vertical supports for the tree and then we took large strips of muslin and dipped them in a sizing solution that we made from water and Elmer's White glue. The first layer of this texture had to pinned to the under lay, but the second layer adhered to the first layer. After we had gotten the two layers onto the tree the whole crew moved to painting the platforms with the elastomeric coating so that it had time to dry overnight.

The elastomeric coating that we used was a new product to us so we were a bit unsure of how fast it was going to dry, and we were uncertain of how many layers was going to need before we reached our desired hardness. The reason we moved to using a new product was 
because of cost. The product that we would usually use in this case is called Jaxsan and cost roughly \$200 for a five gallon container, and the product that we decided to use was called Roof Guard 700 and cost $\$ 75$ for a five gallon container. While we had never used the Roof Guard product we proceeded with some small scale samples before we decided to use it. The first coat

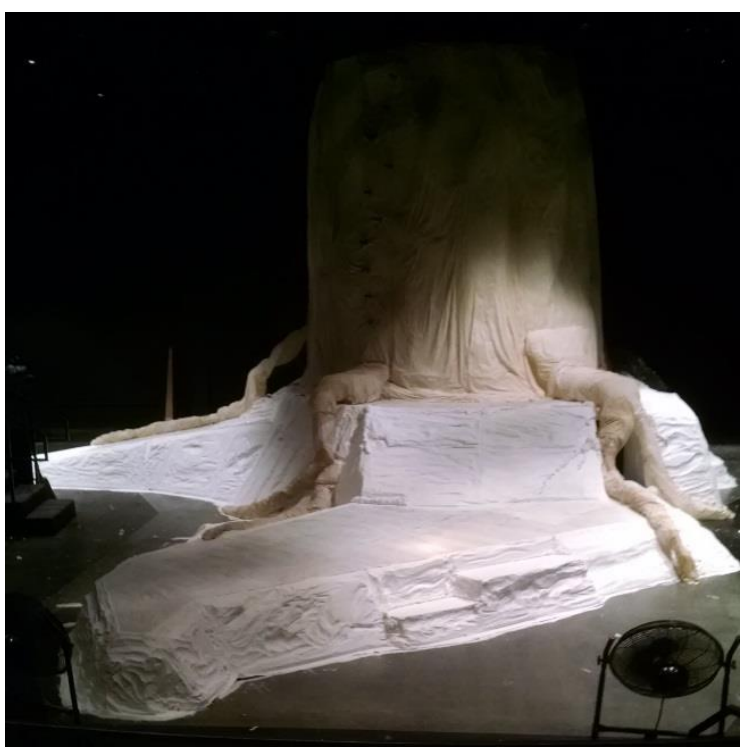

Figure 16: First Coat of Roof Guard that we applied was fairly thick, and we progressively moved to using thinner coats as we applied them until we had a total of four layers. Figure 16 shows what the structure looked like after the first application of the Roof Guard. During this same time period we continued to add pieces to the tree. I had a crew that I instructed to create four large roots that would be attached to the tree and to the ground.

As we finished all these bits and pieces we started to prepare the set for paint. There was not much that needed to be prepared, but we did finish tying the roots to the tree so that the roots looked like they came from the tree and were not just random attachments. Lab was broken down into two groups, one to paint the floor and one to paint the tree. The base coat for the tree consisted of a two color wet-blend that was done between a red brown and a dark brown to give the base variation in the bark of a tree. The base coat for the floor was a three color wet-blend to mimic the floor of the forest. The final step that was applied to the tree was a dry brush that acted as the fine grain lines, and give a last break up on the tree. The floor texture was created by using a sponge treatment of three color variants of the base coat, and was later sealed using a water base sealer with a satin finish. This final layer was applied using a sponge roller so that it was uneven and would have variations across the set. 
While I was working on getting the tree and the floor painted we still had one more major piece of the set that still needed to be finished and installed, and that was the back wall panels. The panels themselves were large pieces of muslin that received a technique using watered down paint so that it would run. The final step to these panels was a set of hand prints that was applied with spray paint using a set of stencils that was made from the hands of various lab classes. I used stencils from as many people as I could get to give the hands on the back drop variation in size, to hint that there are more fairies living in the forest then just the ones that we see on stage.

With tech fast approaching we finished the last few elements that needed work. The only thing that still needed work going into the tech process was the bower unit. The mechanical

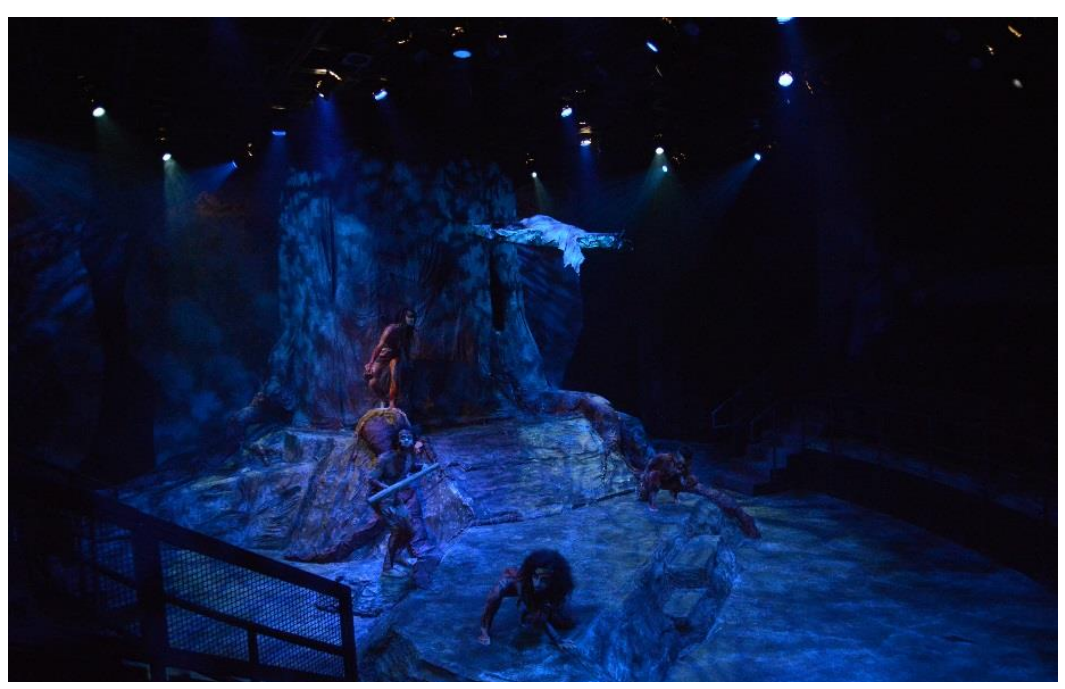

Figure 17: Finished Set portion was set in place and tested, but the overall aesthetic of the basket was something that was still in need of work, and was something that would be addressed throughout the technical rehearsals. Figure 17 shows the set in it completed state during a technical rehearsal 


\section{Section III: Design Implementation: Chapter 8 Tech}

Technical rehearsals were slated to begin on Thursday, November $13^{\text {th }}, 2014$ with crew view; which is the final run through of the show before we start to add all the technical elements to the show. The run through went well, and we finished doing our preparations for implementation of the other elements starting on the following day. For me this meant trying to finish any final paint notes; as well as any notes on items like the bower and the panels that would be used in scene one, scene two and then again in act five.

With these notes done tech started that evening and we stepped through the show. Due to the nature of the set there was not many notes that needed to be taken except a few final paint notes that needed to be wrapped up before I could seal the stage. The bower unit was something that we looked at throughout the weekend, and was something that I used my work calls tweaking. The structure started off by being lined with foam so that the performer would be comfortable while she was in the air. I had then covered the outer shell in fabric and added strips to the underside to give it an organic look. The final piece that was added to it was the wings that when it was lowered to the ground would be spread out to give the piece the appearance of being a large plant that would enfold Titania as she was slept.

As we worked through the weekend the few minor changes that I did to the exterior of the bower still did not seem to bring it into the world the way that I was hoping. I was uncertain of how to change the outer look and make it work. On the Monday following our tech weekend Professor Klingelhoefer and I were looking at the bower, and he made the suggestion of stripping it all the way back down to the steel basket and starting from scratch. In our conversation we talked about how there was an organic nature to the basket, and if I could do something that would keep that visible adding to the organic nature of the structure. What we came up with by 
the end of our conversation was to layer pieces of plastic; that would shrinkk when heat was applied, over the top of the wire structure to give the bower the look of something the fairies constructed for Titania. The final piece that was added to the bower was the poly silk that was used to enfold Titania. These piece were taken and the edges were cut to have a tattered look, and then they were painted along with the interior for a faded look.

With the bower modifications completed we proceeded into tech that night, and by the end of the rehearsal both Professor McGonigle and I were happy with the modifications that we made to the bower. With the conclusion of rehearsal on Monday there were only a few minor notes that had to be taken care of before final dress on Tuesday and the opening of the show on Wednesday of that week. All in all the technical rehearsals for this show were fairly straight forward with minor notes once the bower modifications were done. 


\section{Section IV: Reflection: Chapter 9: Looking Back}

With the conclusion of every design I find it an important practice to take some time and look back not just on the final product, but also on the process that lead to that decision. Each show has its own unique challenges that need to be overcome throughout the design process, and it is these challenges that make seeing the final product on stage so rewarding. A Midsummer Night's Dream was a show that some of the challenges came to light fairly early on in the process, but there were also some challenges that snuck up on me. I will be going over some of these challenges, and also going over some things that I wish I would have done differently throughout the process.

The first challenge that I will be addressing is the change in my design process for this show. While this might not seem like something that would be a major issue it was something that put me in a tight spot when it came to getting the level of detail in drafting that I would have liked to produce. My preferred process is to work with some sketches to get a handle on the aesthetic and structures, and from there I would normally move into a CAD program and work on developing a 3-D model of the space and set to see how it all relates. Once I have the physical world model roughly in a digital form I usually move on to building a physical model that helps me make sure all the relations that I see in the digital form will work.

For this show I moved to the physical model fairly early. This allowed us to play with physical pieces and see how they related to each other in a scale model. From pictures of the physical model I was then able to take and add elements in Photoshop to give us renderings to see what the world might look like. One of the things that I have tried to adopt through the various design classes and experiences is to be flexible when you are working on designing; especially while it is in its early stages. As we pushed ever closer to our due date for the design, 
and we had yet to solidify an idea for the main elements of the set. I began to get worried about how much time I would have to complete the drafting that would be used by Professor Neuenschwander to budget and build the set. While normally I would be creating the renderings of the world off a digital model that I could clean up and use for my elevations this as not the case for this show. So when it came time to finally draft the set I struggled to get the detail that I would have liked partially due to time constraints, and partially because I struggled as I worked backwards from my preferred process.

I also struggled to communicate all the information that I would have liked to give the shop in my drawings, and struggled to communicate with Professor McGonigle about some of the detailed items in the set. The piece that I struggled with the most was the bower unit, and this became an issue as we got closer, and closer to tech. Communication of details like this is something that is extremely important in the relationship between the scenic designer and the director, and in this case is something that I failed at. From this I have learned how important it is to be exacting in the details that are given and have formulated some questions and some strategies to help keep all the details straight as we go through the design process.

All in all it is the challenges that must be overcome throughout the design process that make a show into what the audience sees on the stage. Throughout the process for this show we pushed out in many different directions and came back to the original idea that both Professor McGonigle and I had at the start of the process. The road to this design was reflective of the transformative nature that ran through the heart of the script. It influenced us even though we did not know it was doing so, and it was the transformation of ideas that let us see what this show needed in the end. 


\section{$\underline{\text { Appendix A: Research Photos }}$}

\section{Angkor Wat \#1}

This images was the inspiration for the initial idea of single tree, and became important as I moved into the final redesign.

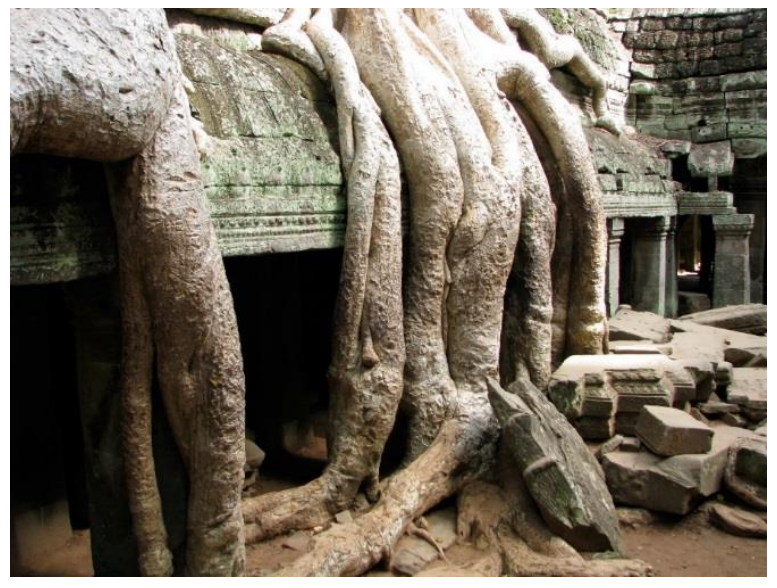

Grasping Tree

The primal nature of this image gave Professor McGonigle and I the idea to return to single tree in our final redesign.

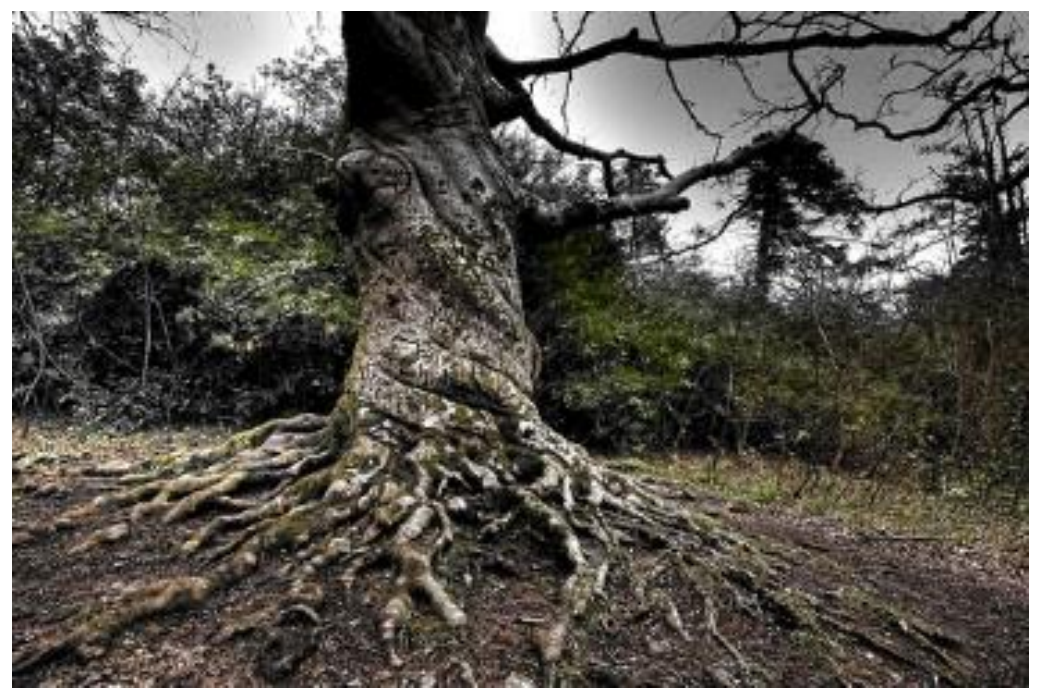


People of the Omo Valley

These two images are stills from the video that Professor McClung found and became our inspiration as to what the fairies might look like.
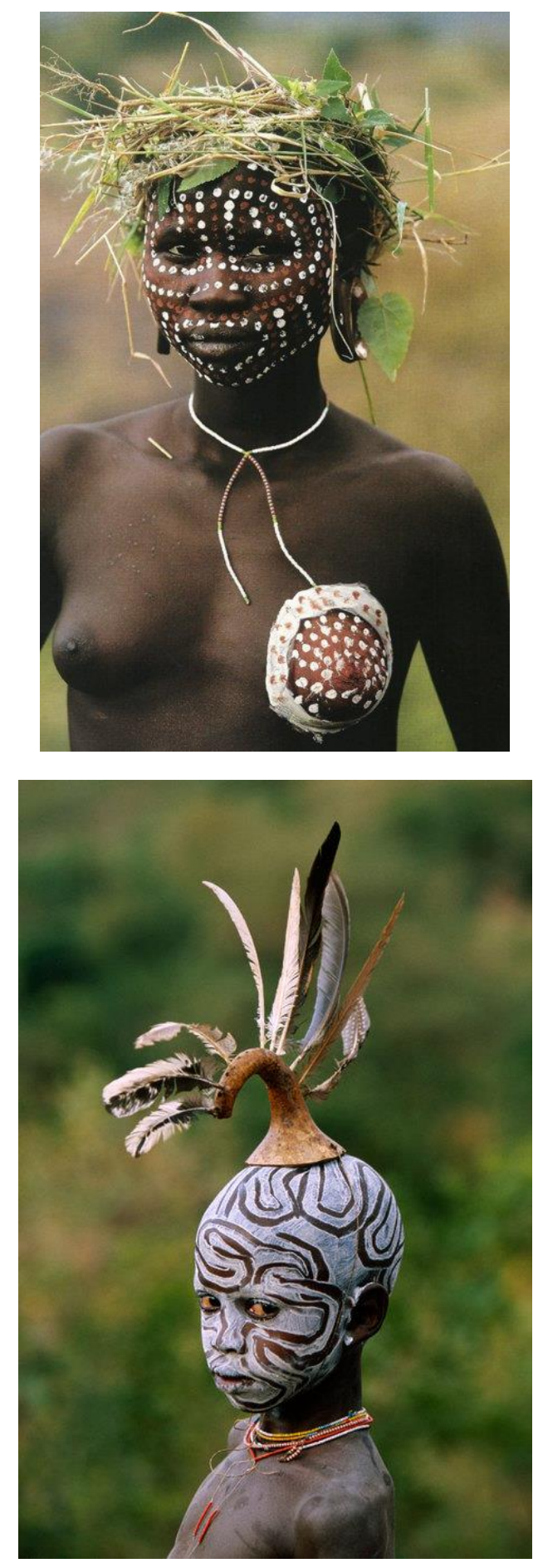


\section{Angkor Wat \#2}

This image of Angkor Wat was one that I found later in the process and helped give me the idea of having an opening in the tree that the fairs could climb out of.

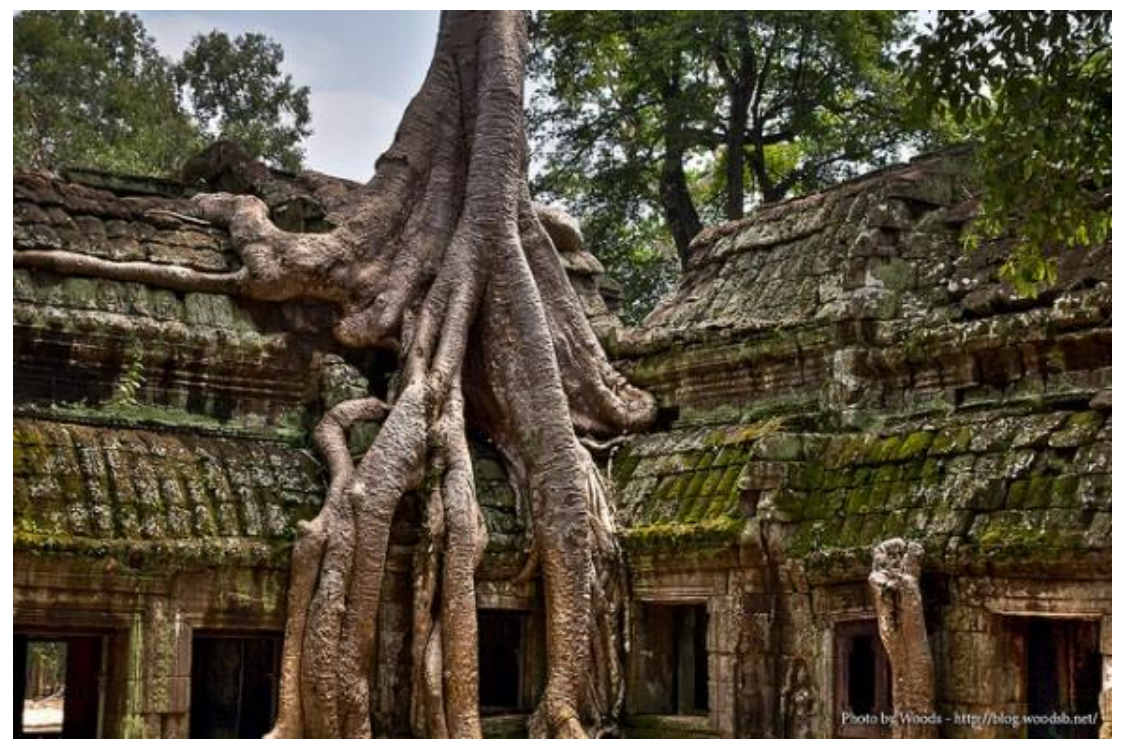

Car Reclaimed

As I was working through the first redesign I had the idea that the bower might be something that was reclaimed by the world. The image below was the result of one of my brainstorming sessions on the type of items that the bower could be made from.

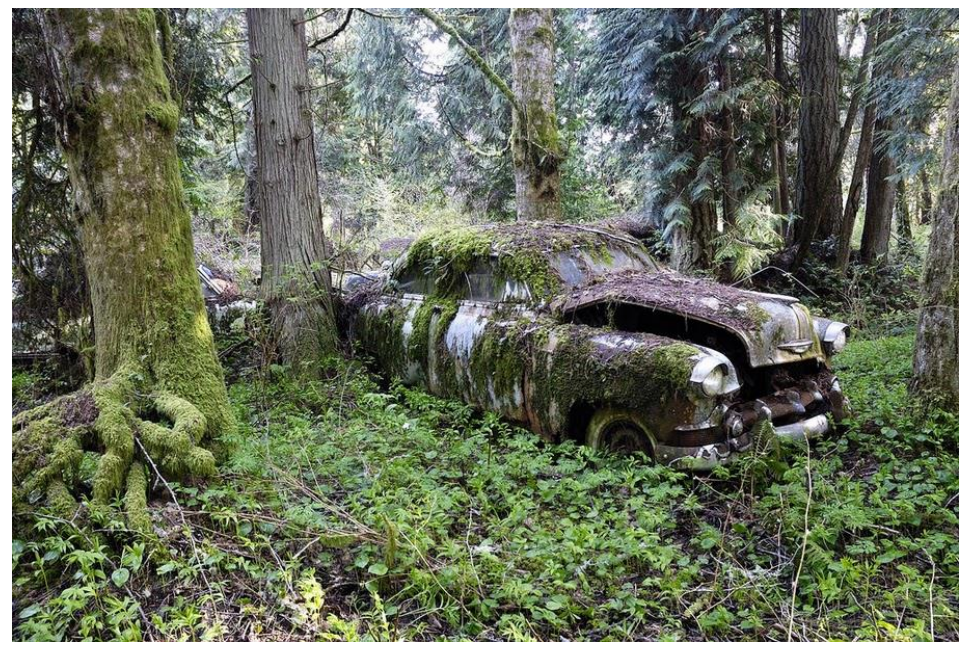




\section{Art Nouveau Ladies}

The Art Nouveau Ladies were used early on to show how Art Nouveau used lines to create a sensual look, and to show what parts I would blend into other elements in the original design idea.
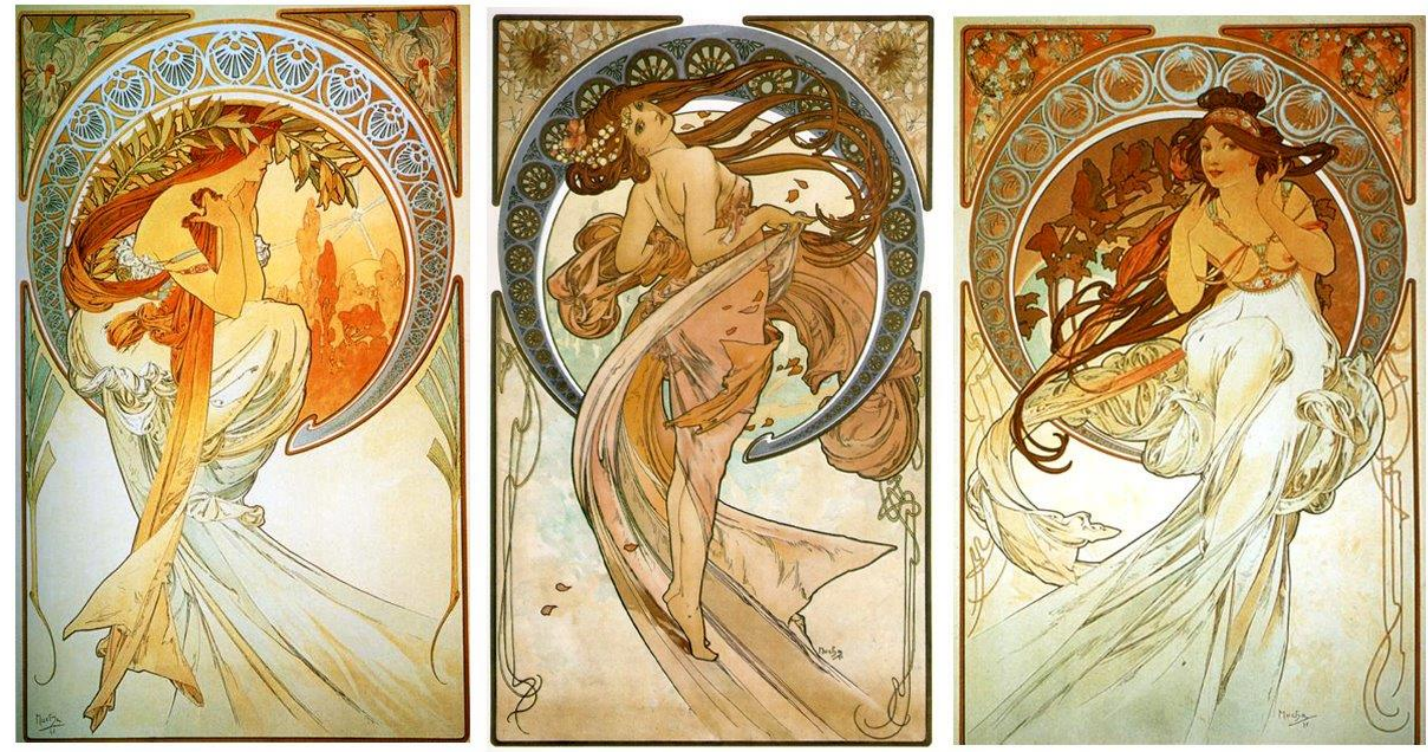

\section{Art Nouveau Lamp}

The Art Nouveau Lamp was used in early conversations with Professor McGonigle to show how we could possible blend the human form with nature.

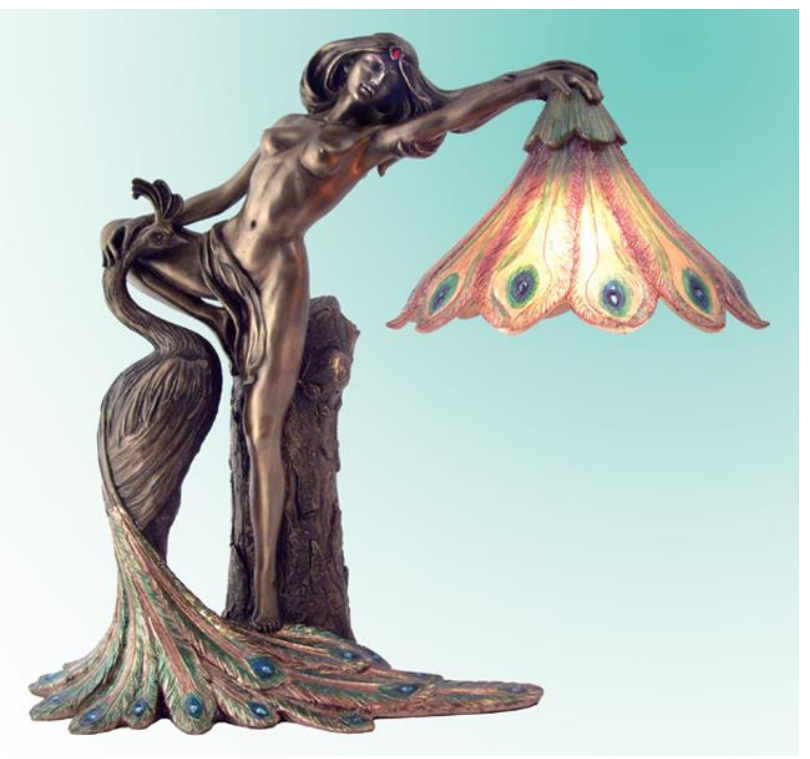




\section{Cave painting}

This piece of research was the inspiration for back wall panels. It was something that stuck through many iterations of the design as it was something that I felt help tie the two worlds together.

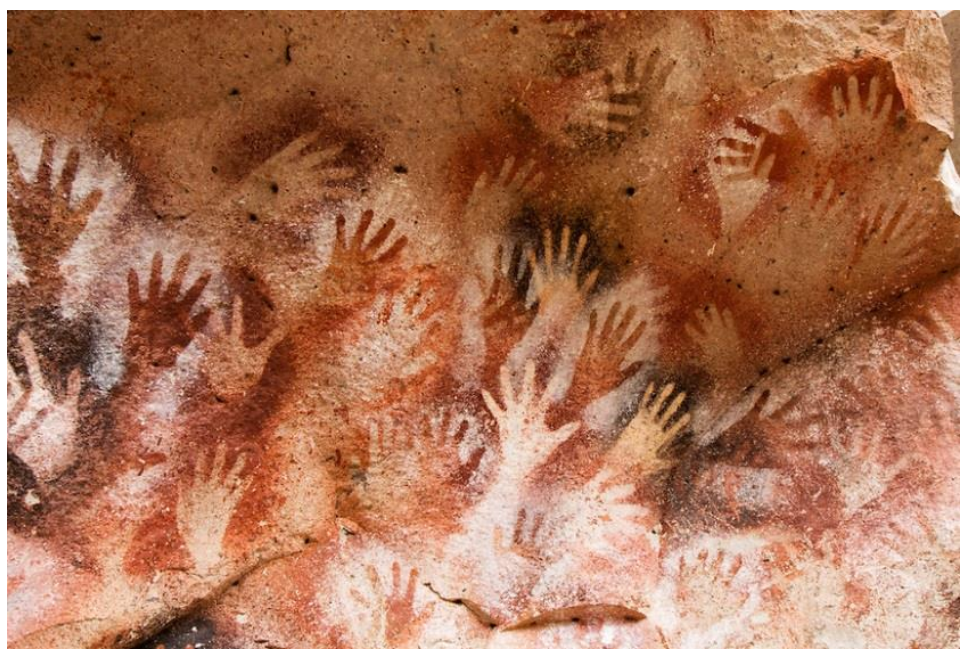

\section{Art Nouveau Door Way}

The blending of natural elements and architectural structure was something that drew me to it early on. As we moved away from blending the two worlds this image became less important.

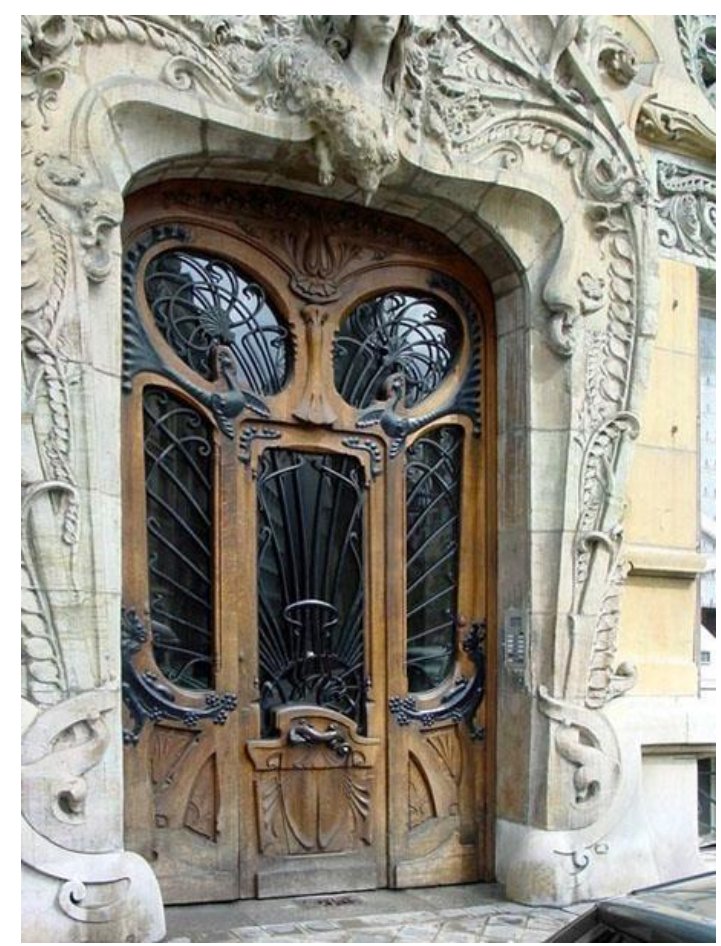




\section{Human Nest}

After moving away from the initial design idea and into something more of a metaphorical forest the Human nest became important in the design as the bower unit.

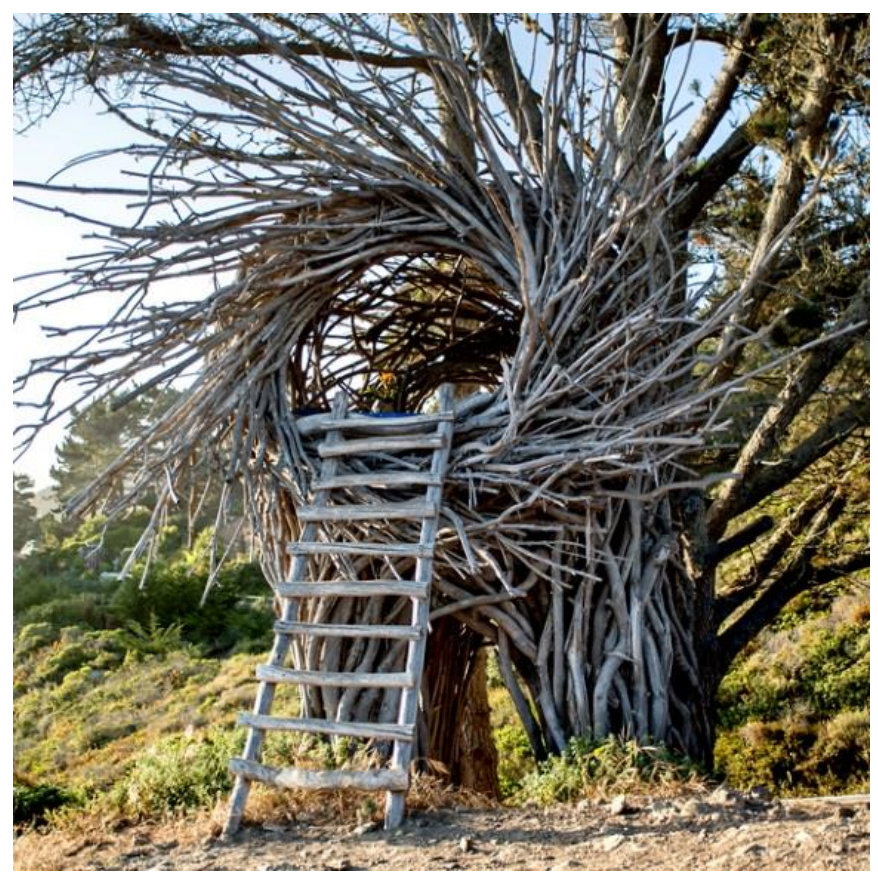

Tree Ideas

As we revisited the idea of an organic world the image below became an image that stuck with me a possible over all texture of the tree

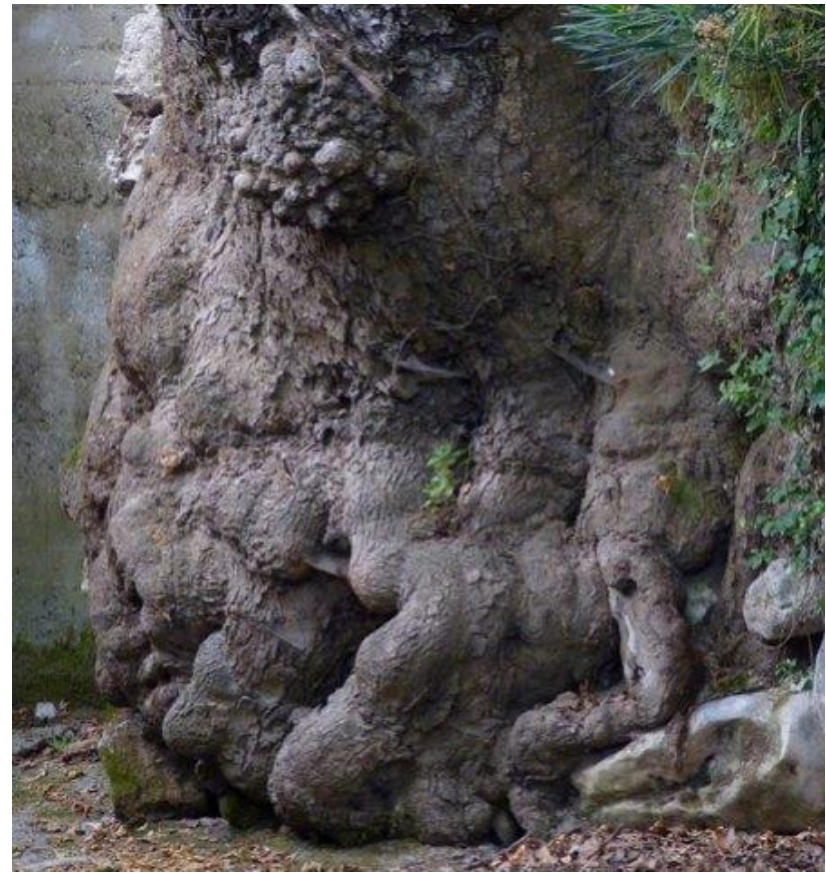




\section{Venus Fly Trap}

Both of the images on this page became important to me as ideas for what the bower might be, and what it might represent.

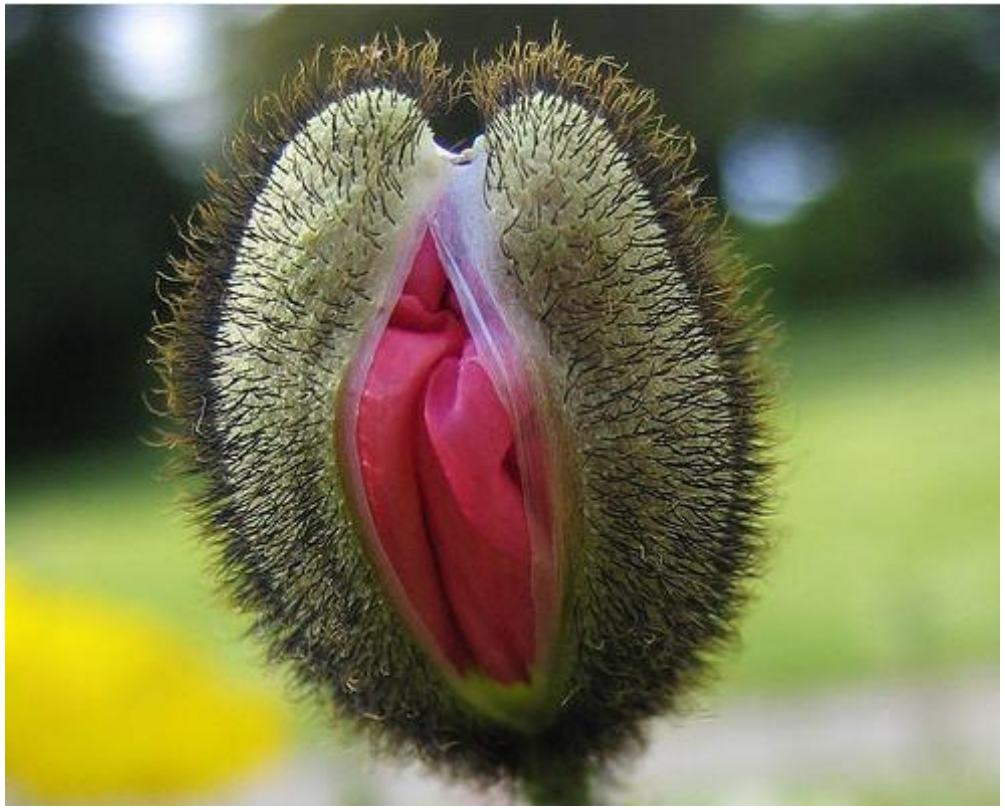

Lady Slipper

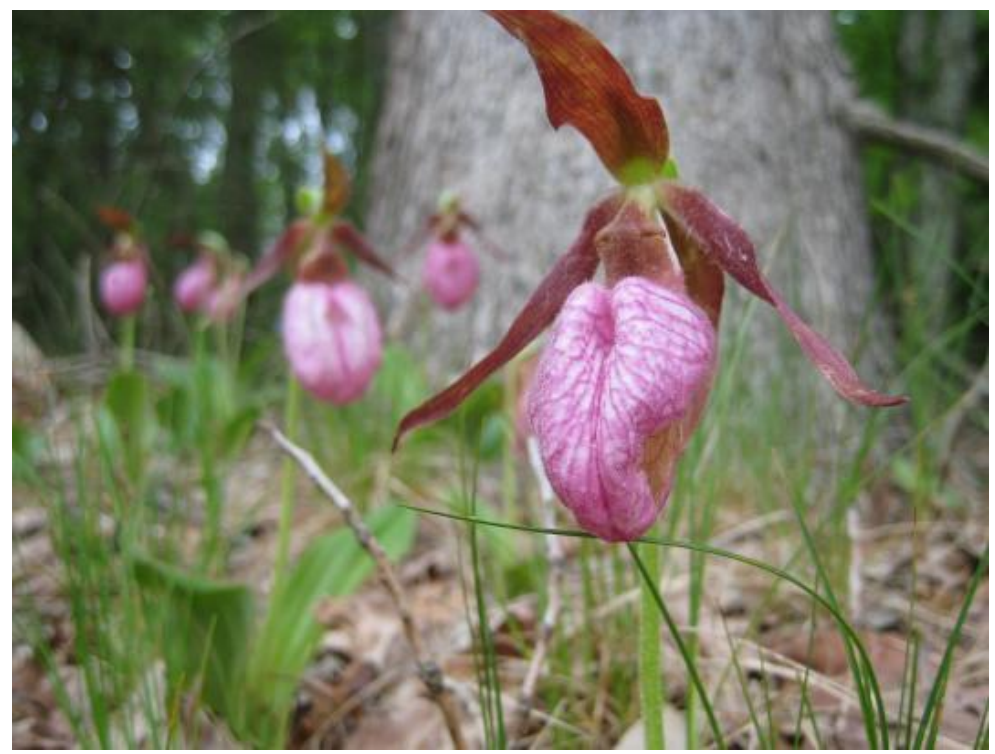




\section{Art Nouveau Stairs}

This image was important in the initial part of the design phase as it was a representation of how I might be able to blend the human and the fairy world using the Art Nouveau style.

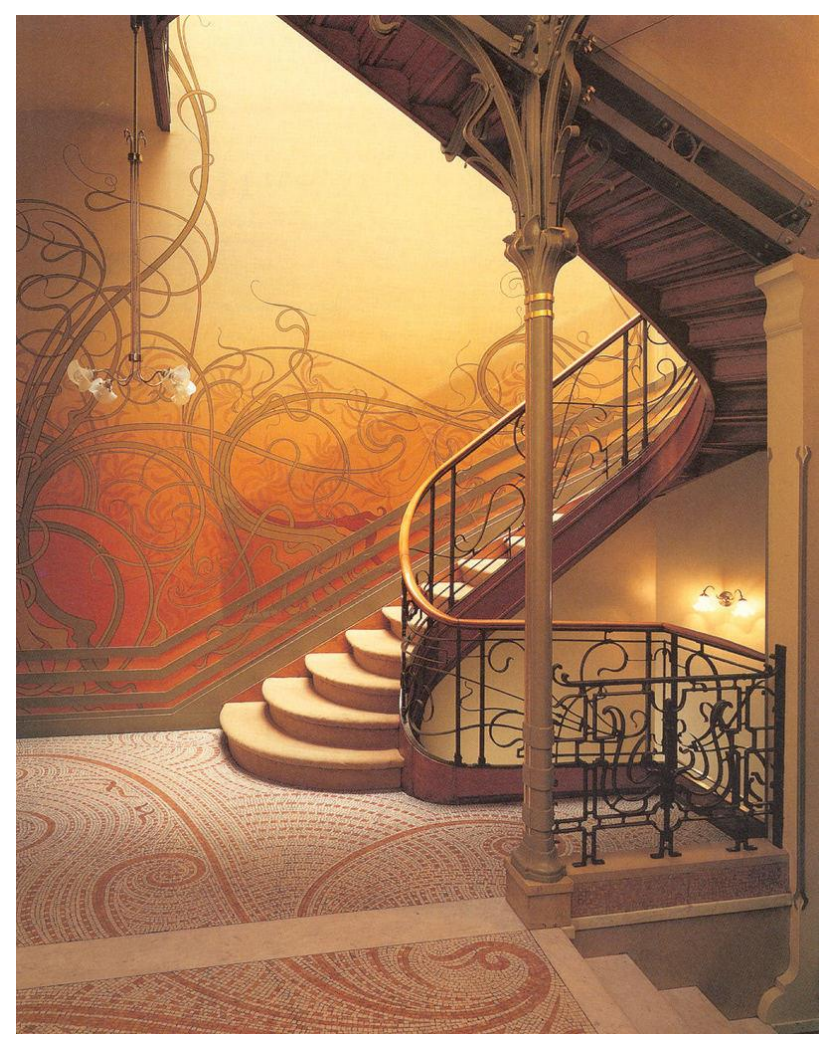


Appendix B: Renderings/Draftings

Initial Tree Sketch

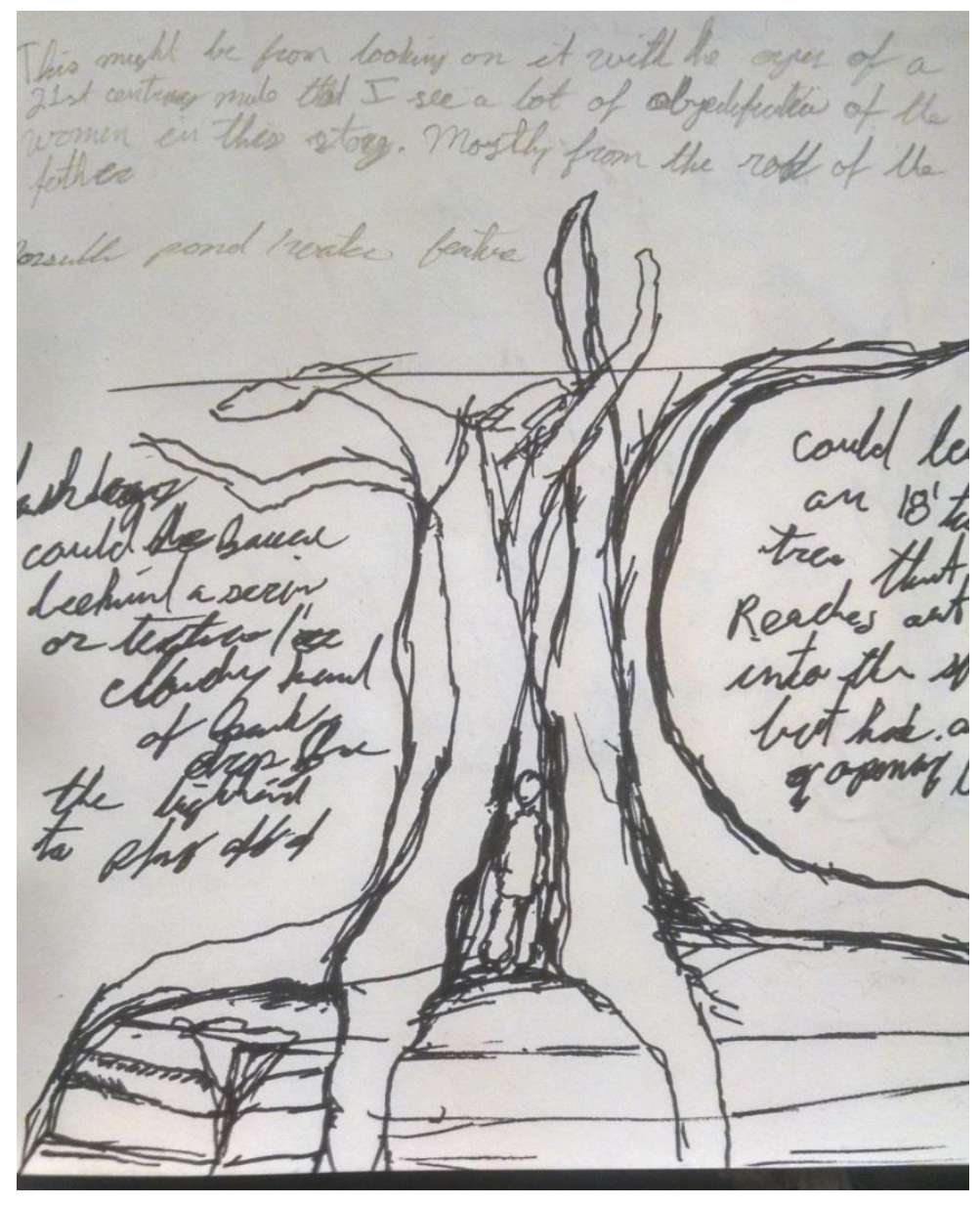


Initial Tower Sketch

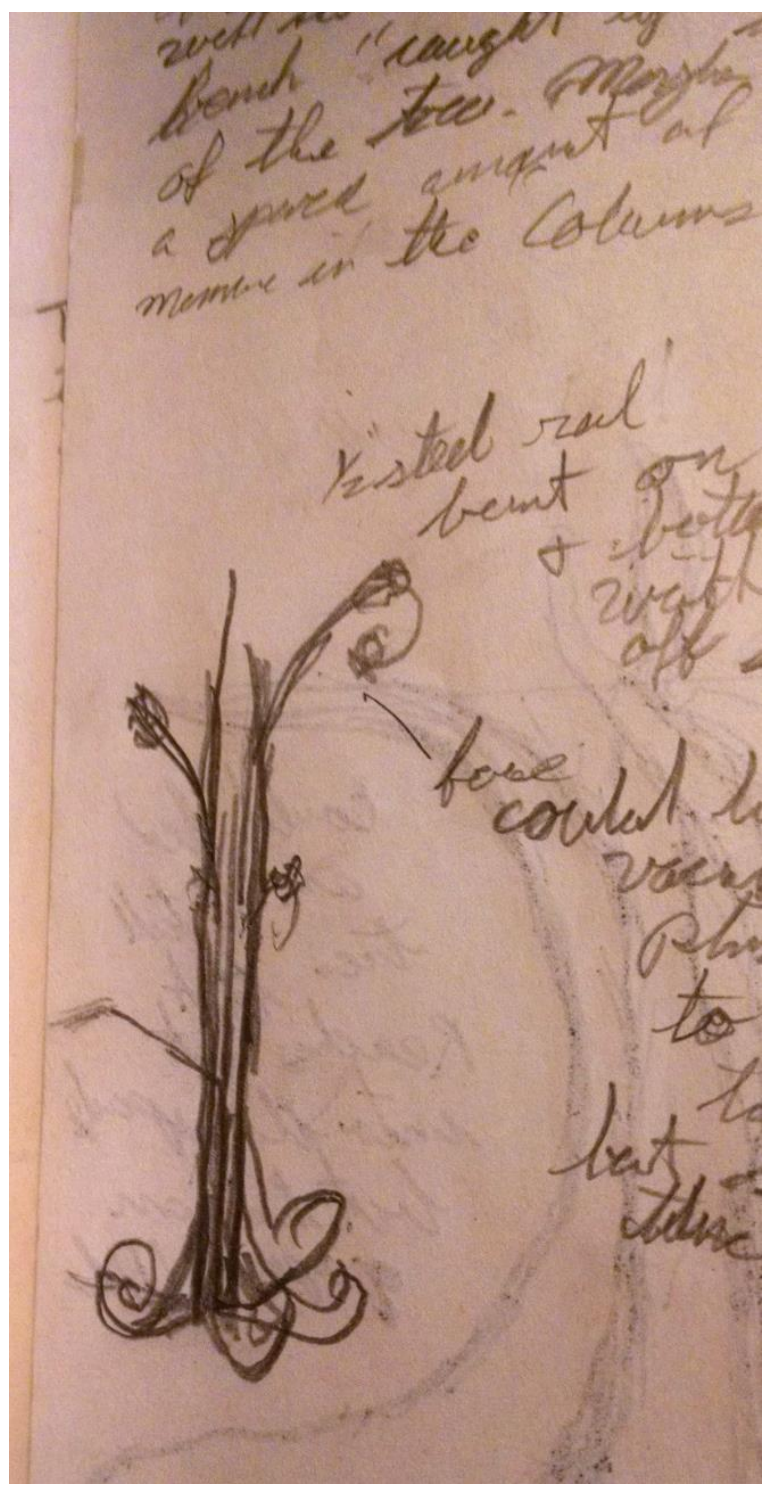


First Photoshop Render

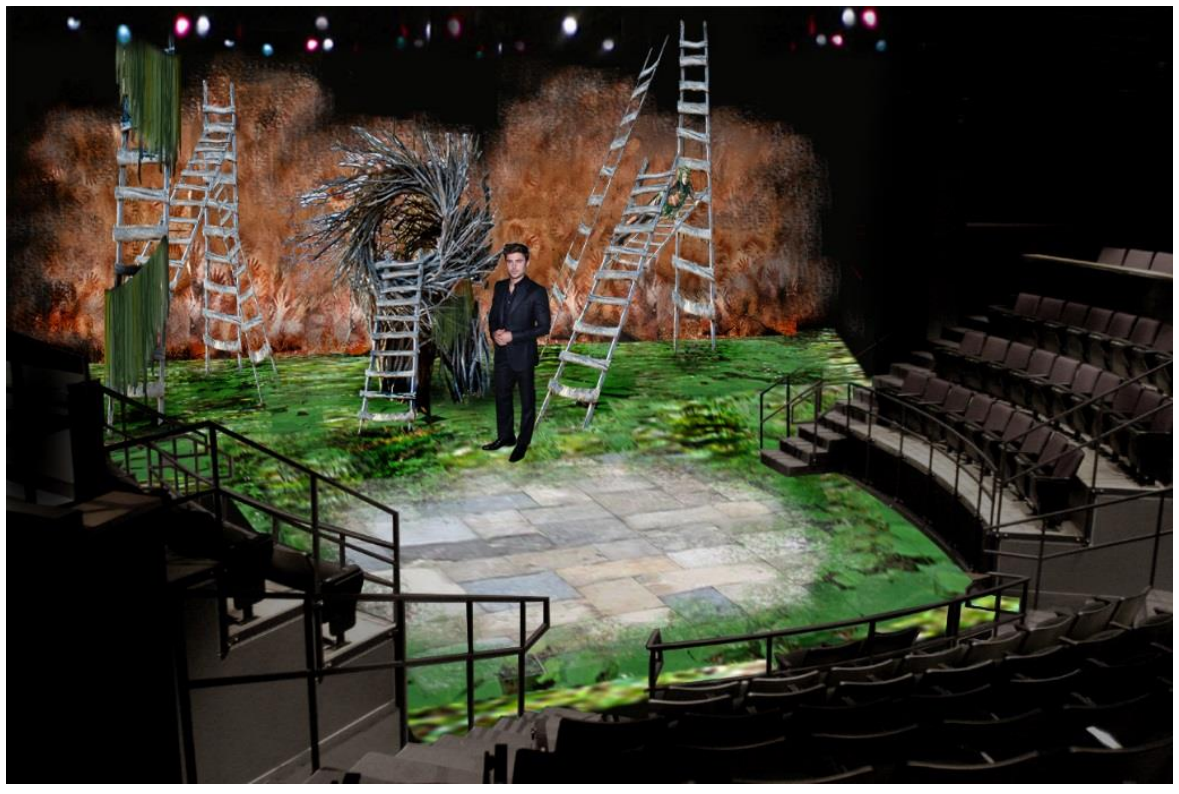

Initial Redesign Render

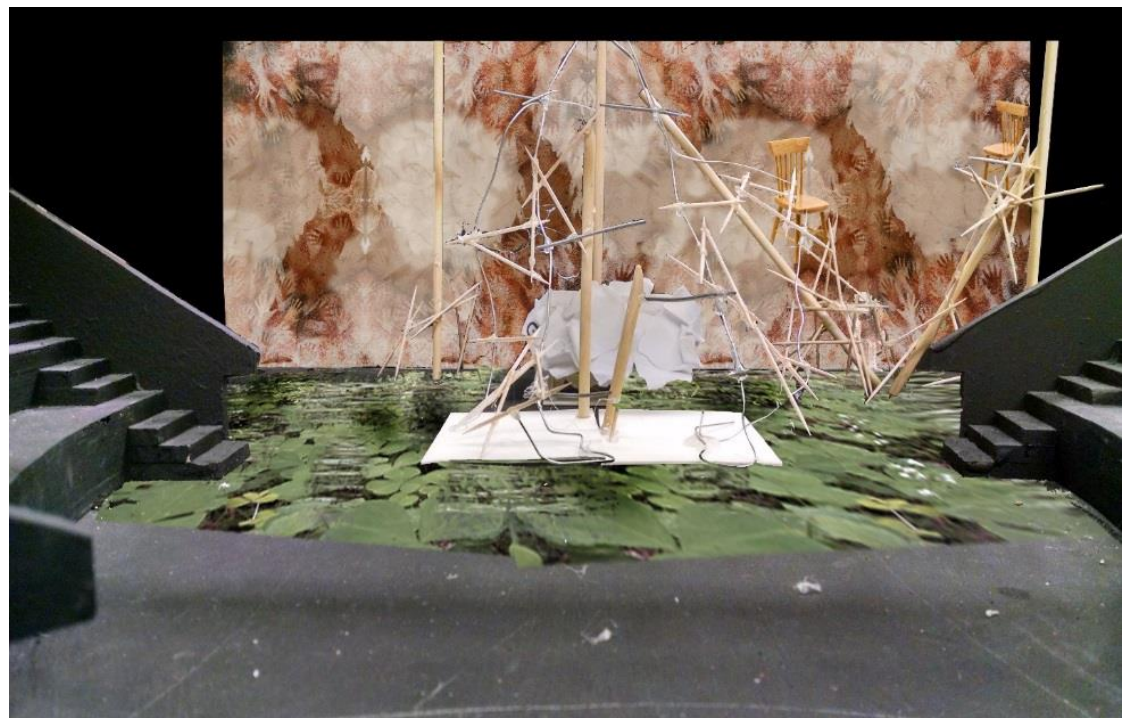


Redesign Render 2

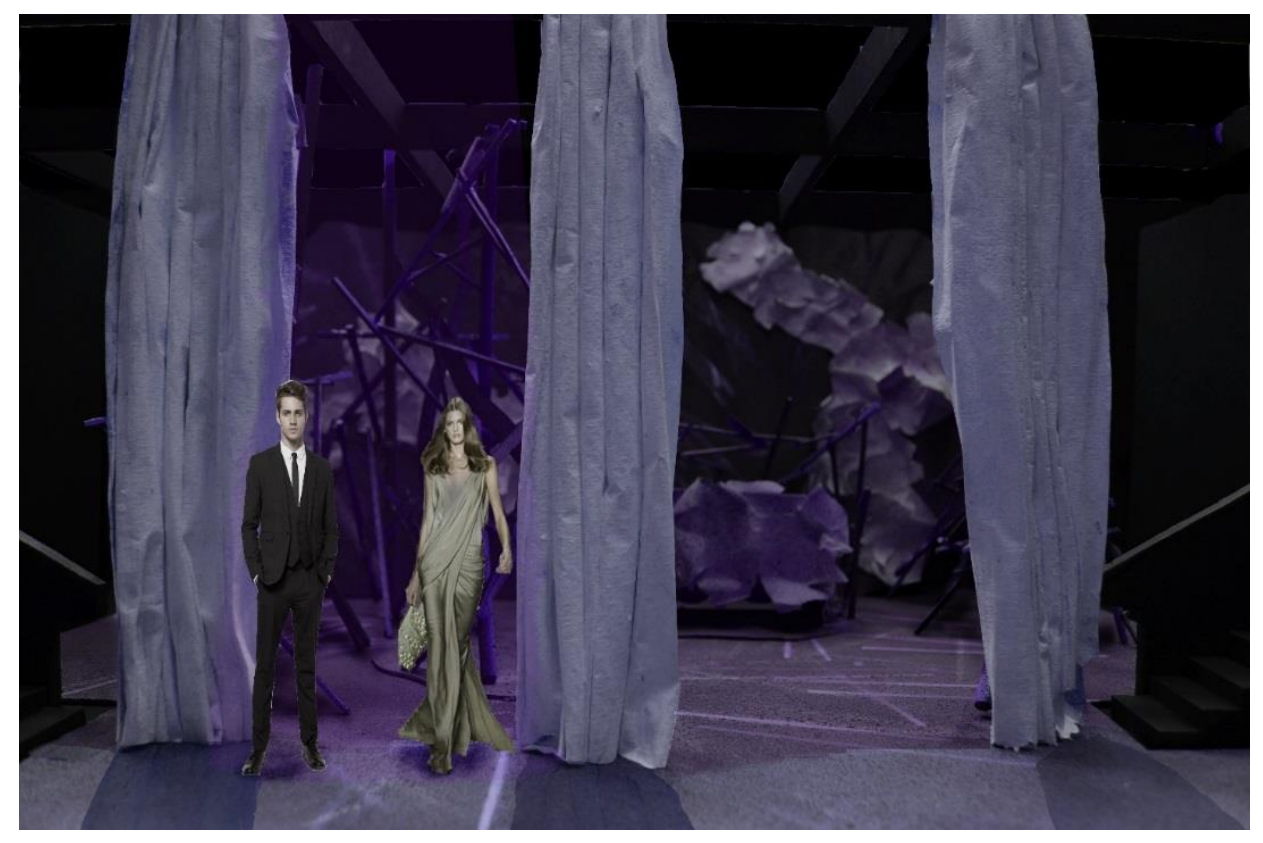

Redesign Forest Render

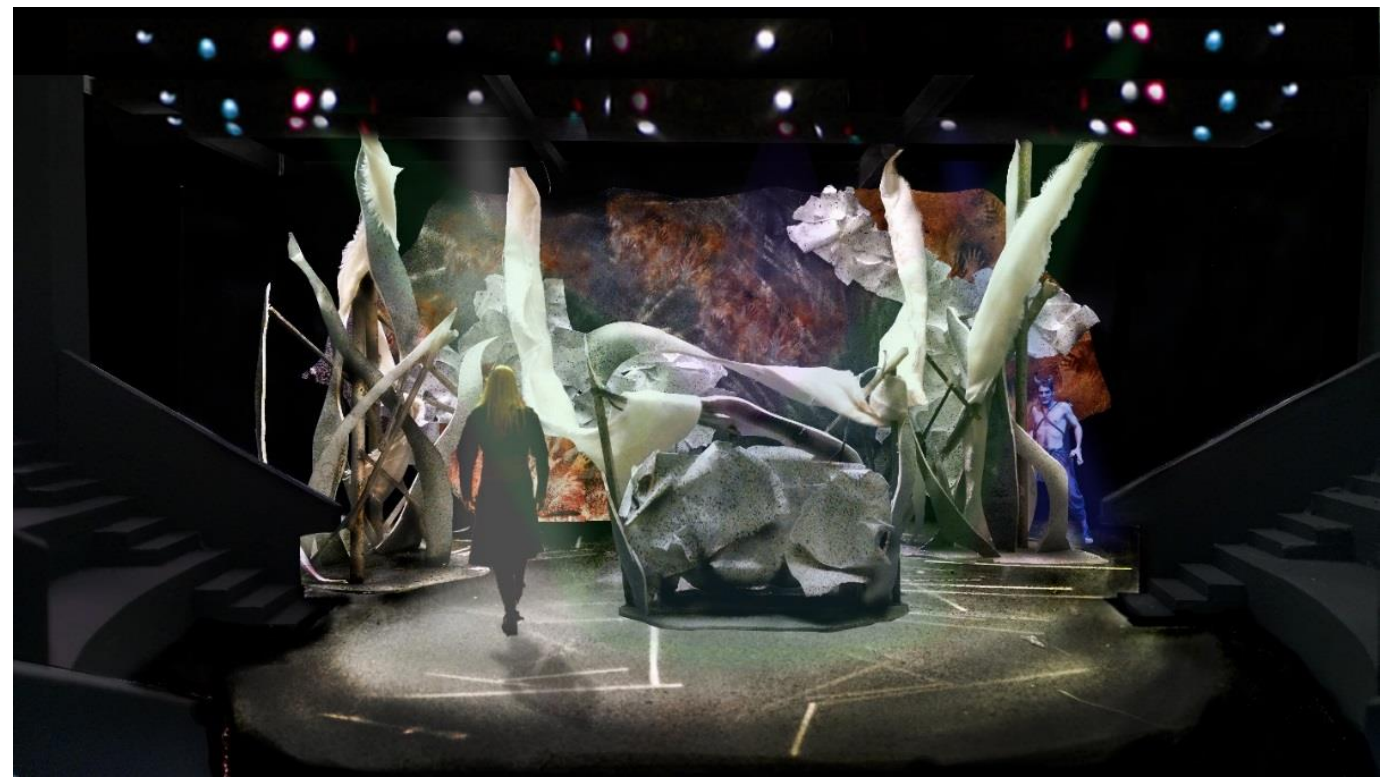


Second Redesign Initial Render

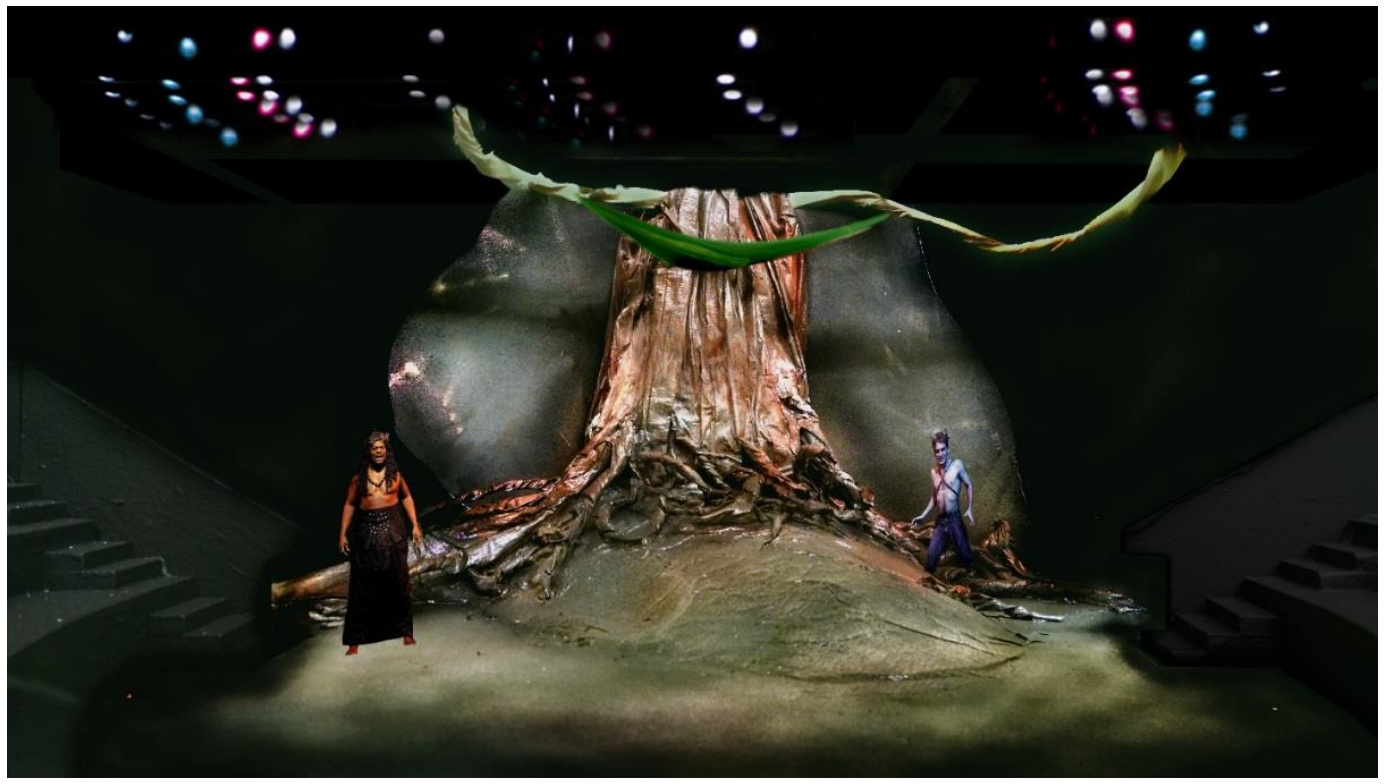

Second Redesign Render \#2

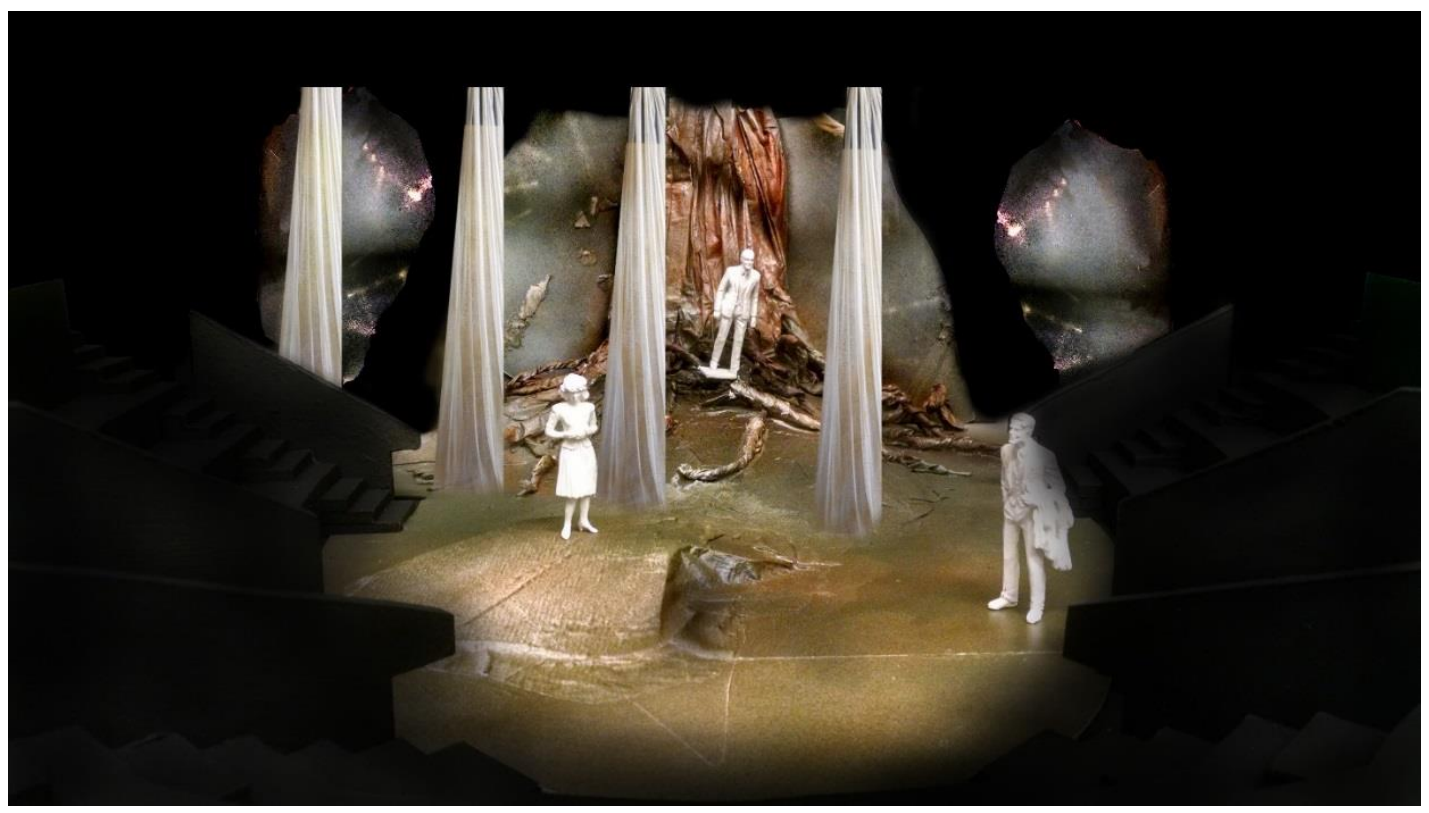


Final Desing Render

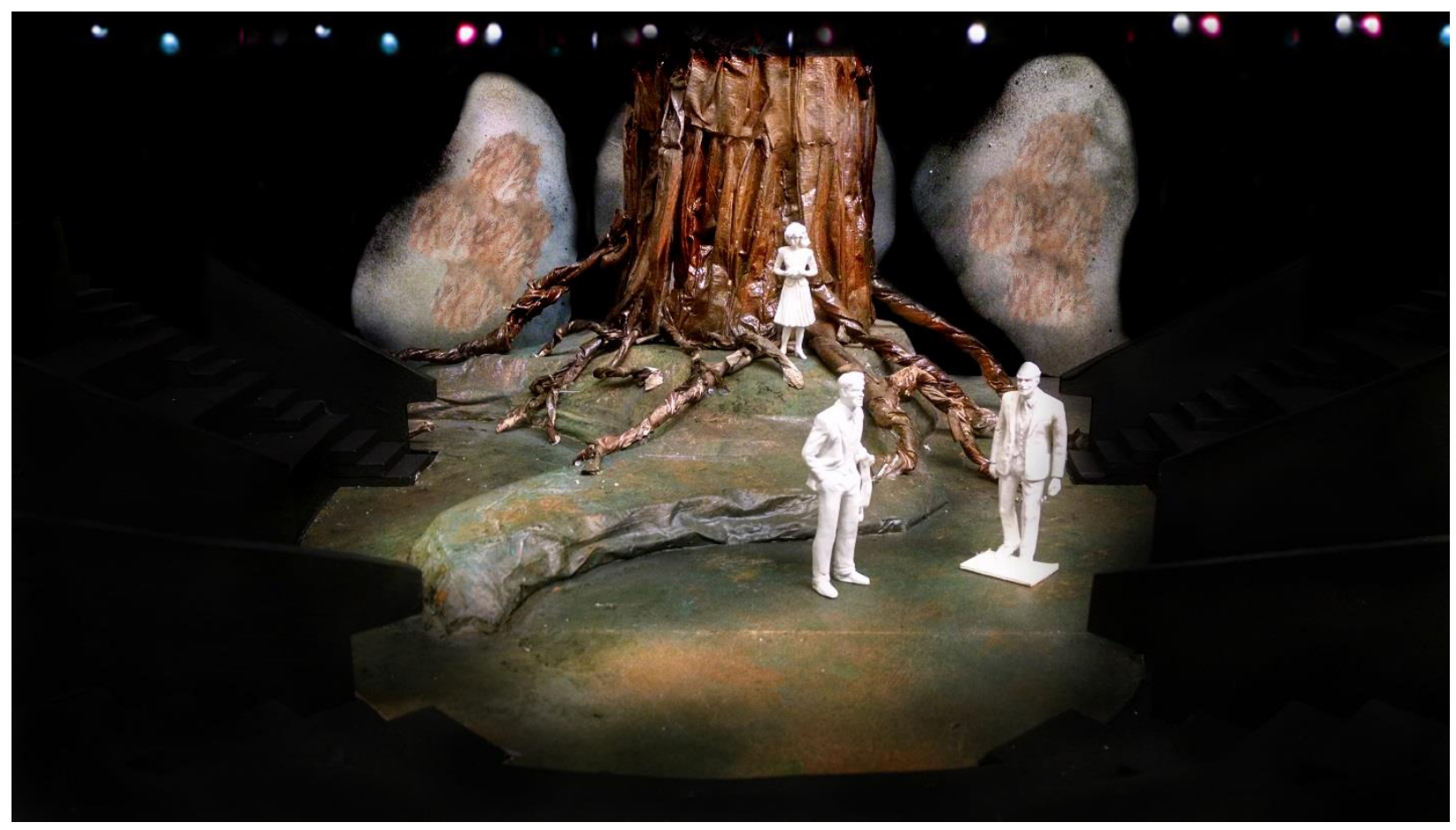




\section{Ground Plan Drafting Plate}

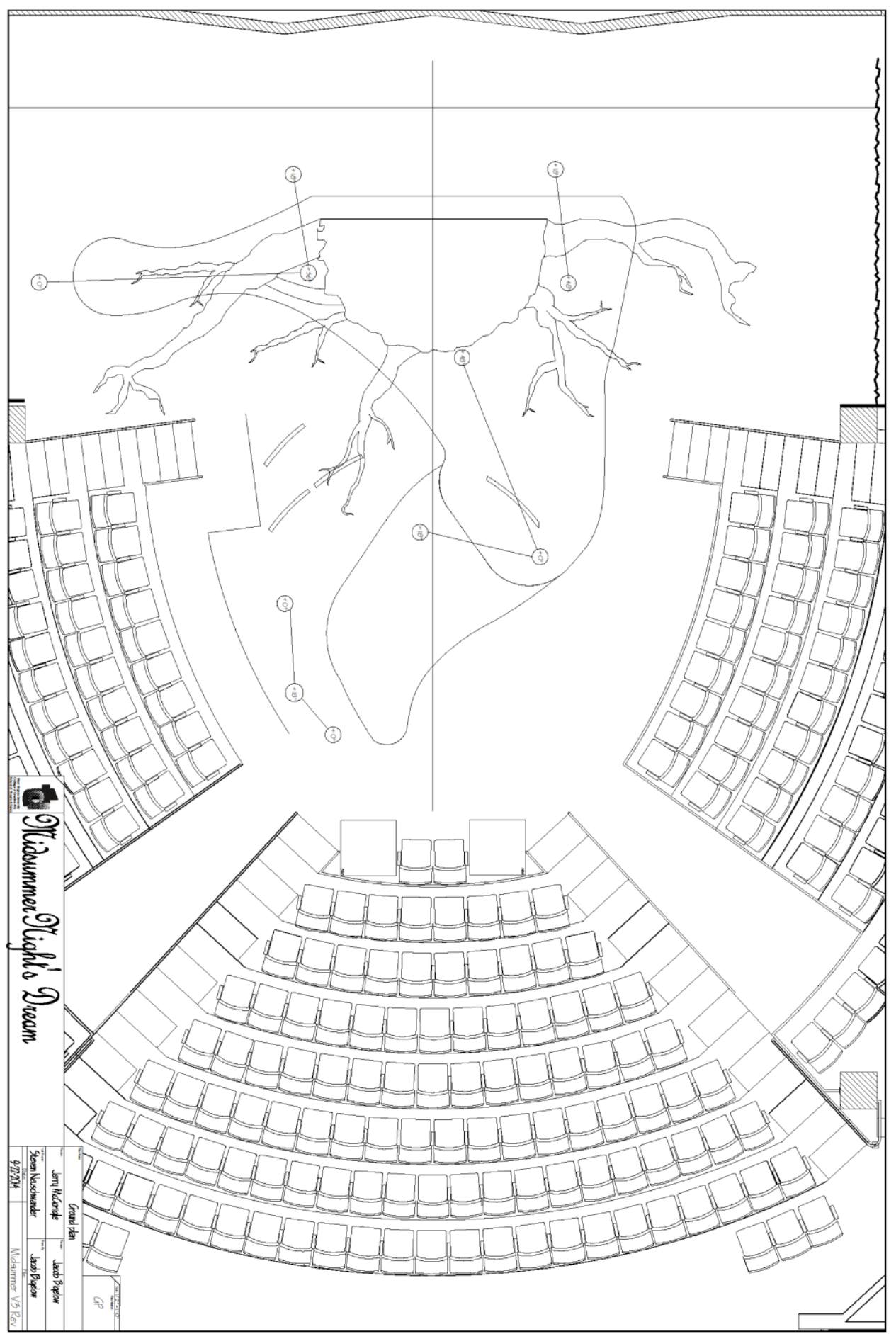




\section{Tree Drafting Plate}

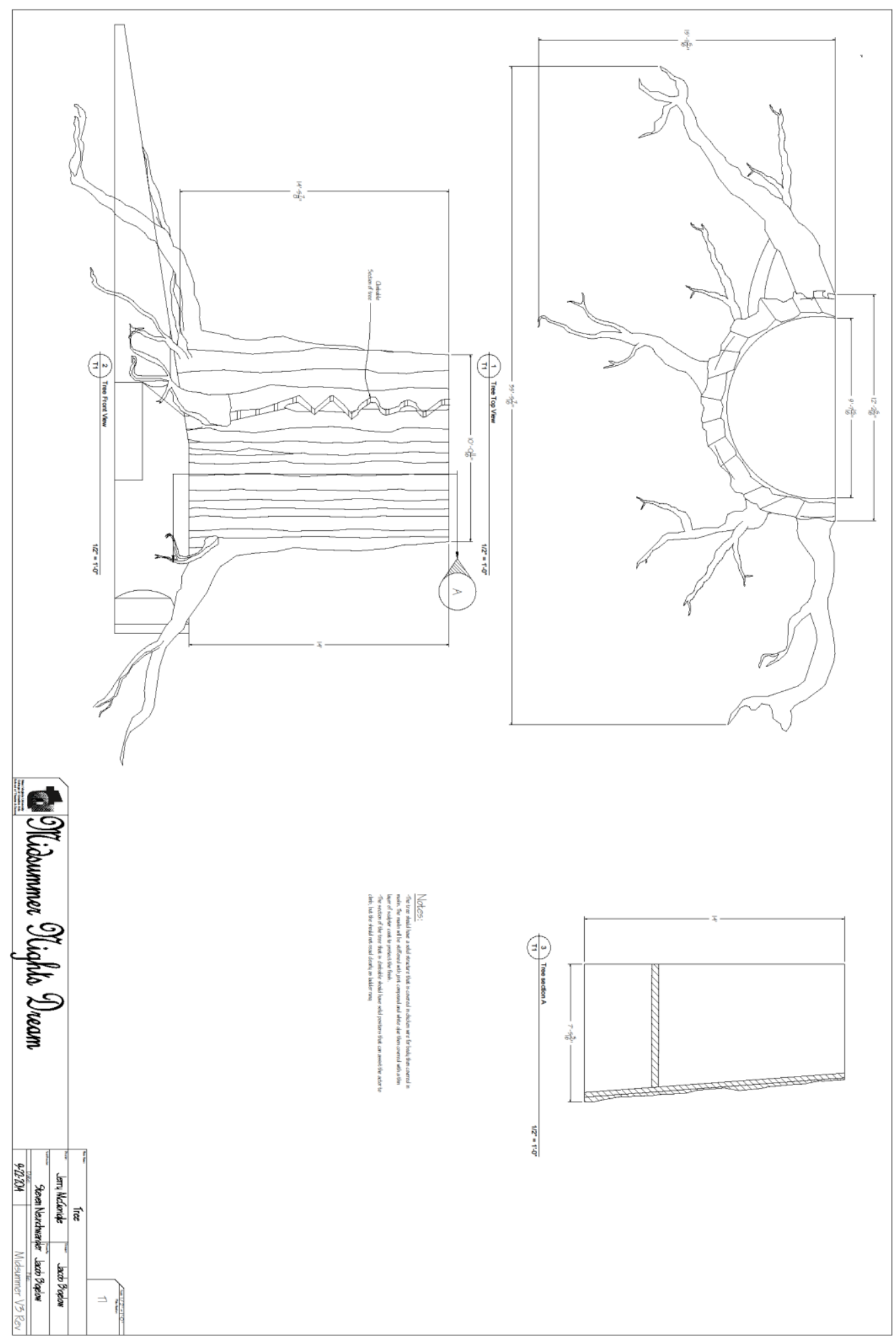

$51 \mid \mathrm{P}$ a g e 


\section{Backwall Panel Drafting Plate}

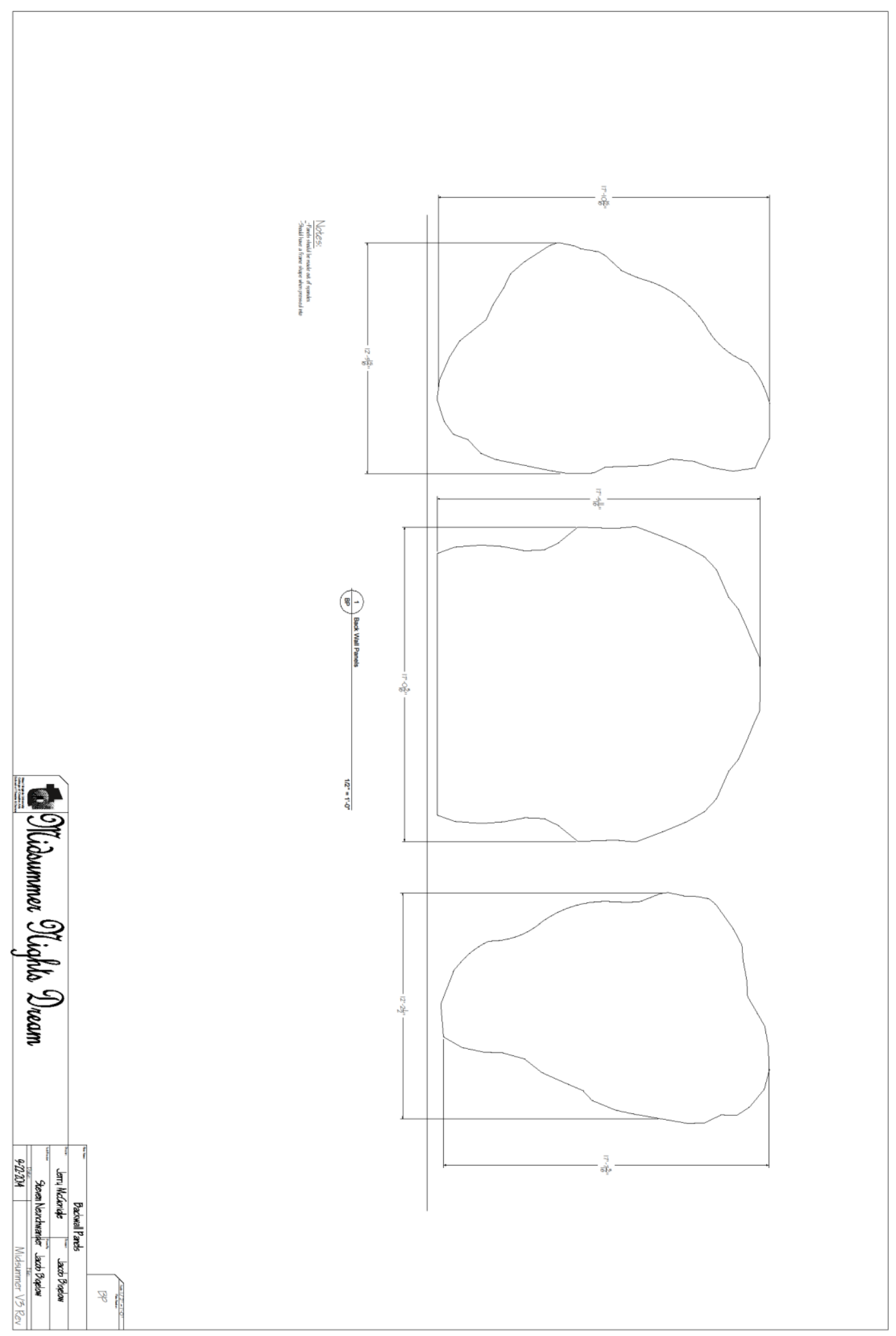

52 | P a g e 


\section{Hill Platform Drafting Plate}

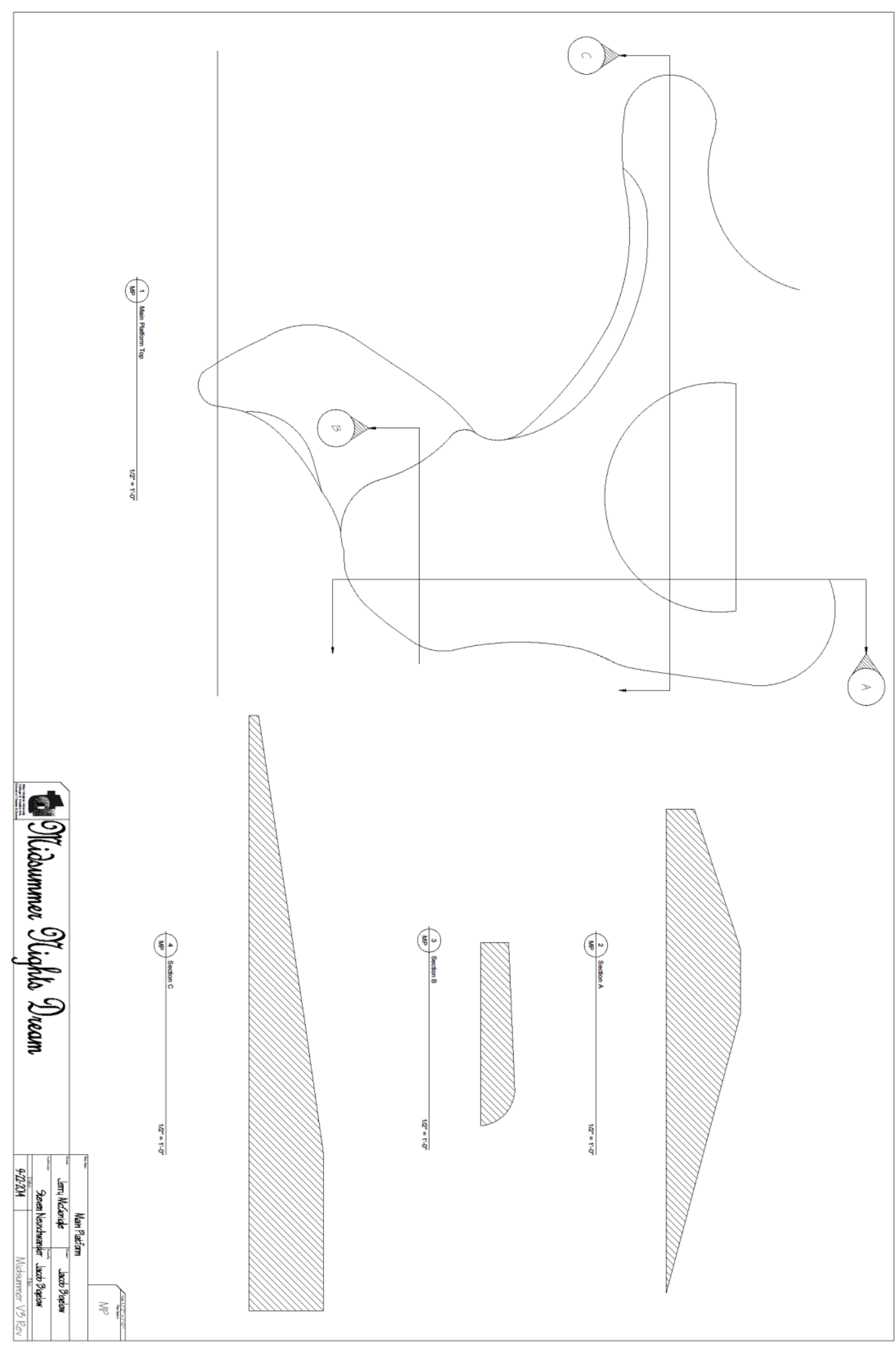

53 | P a g e 


\section{Lower Deck Drafting Plate}

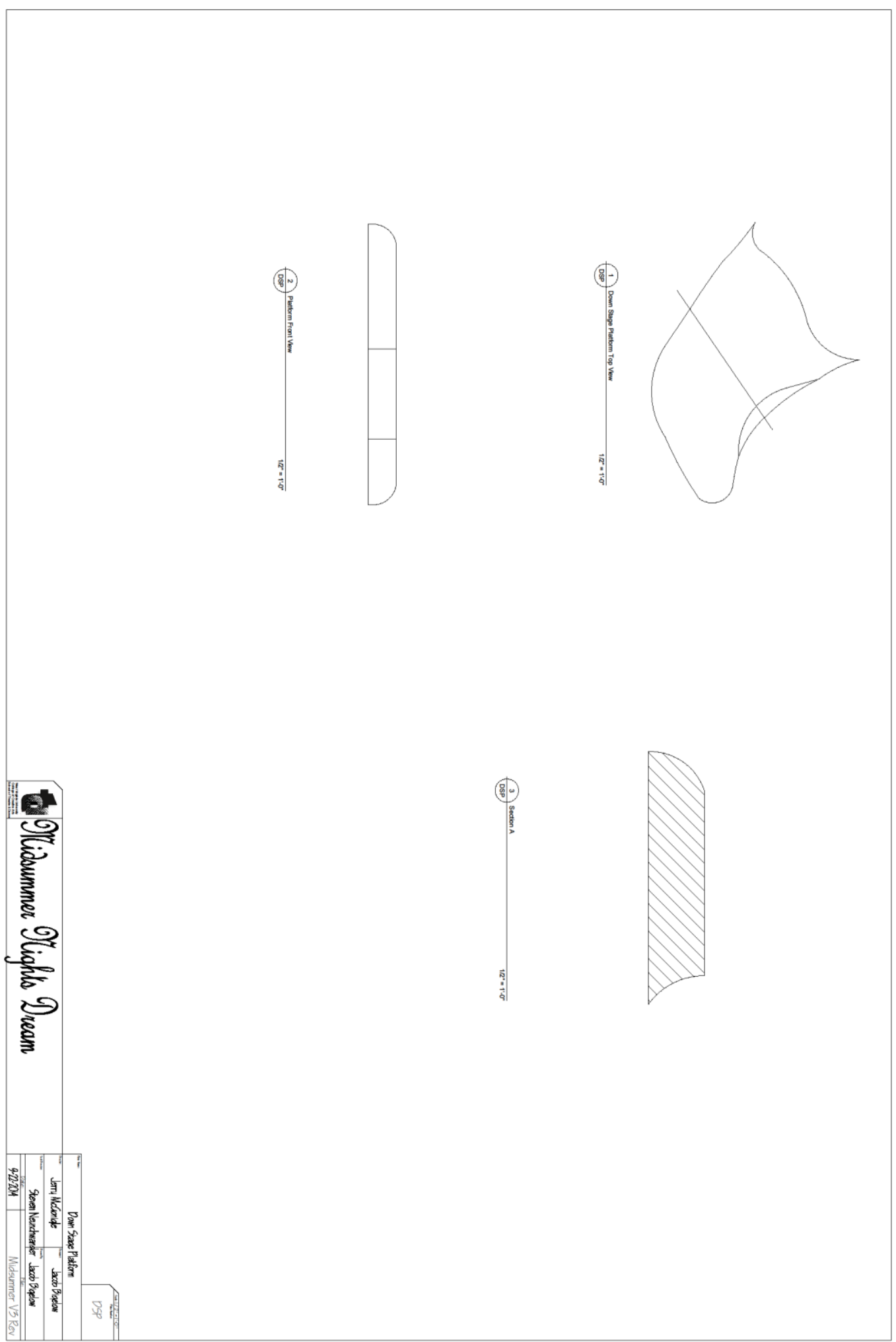

54 | P a g e 
Athens Panels Drafting Plate

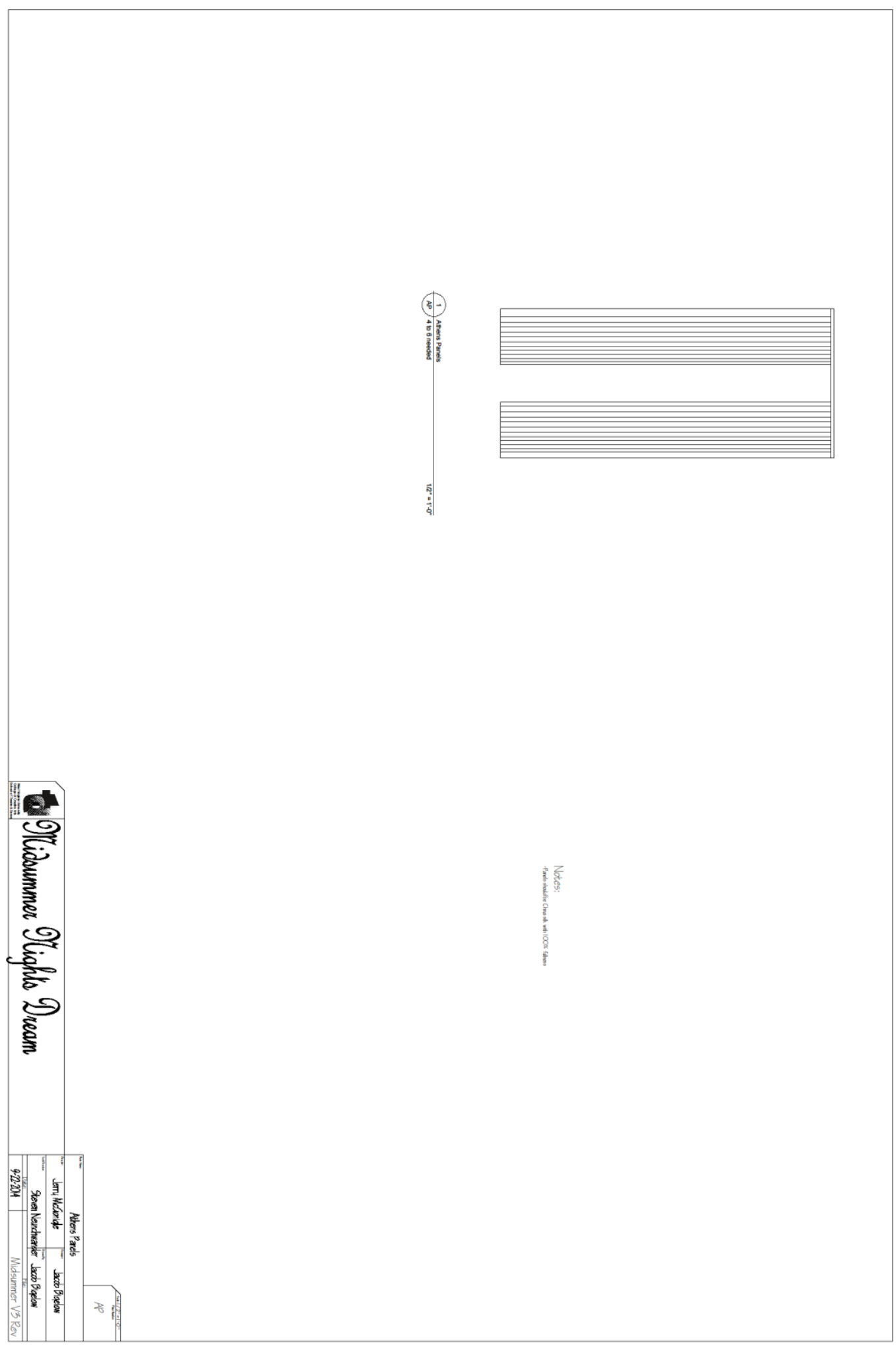

55 | P a g e 


\section{Appendix C: Production Photos}

Act 1 Scene 1: Hermia Confronting Thesus

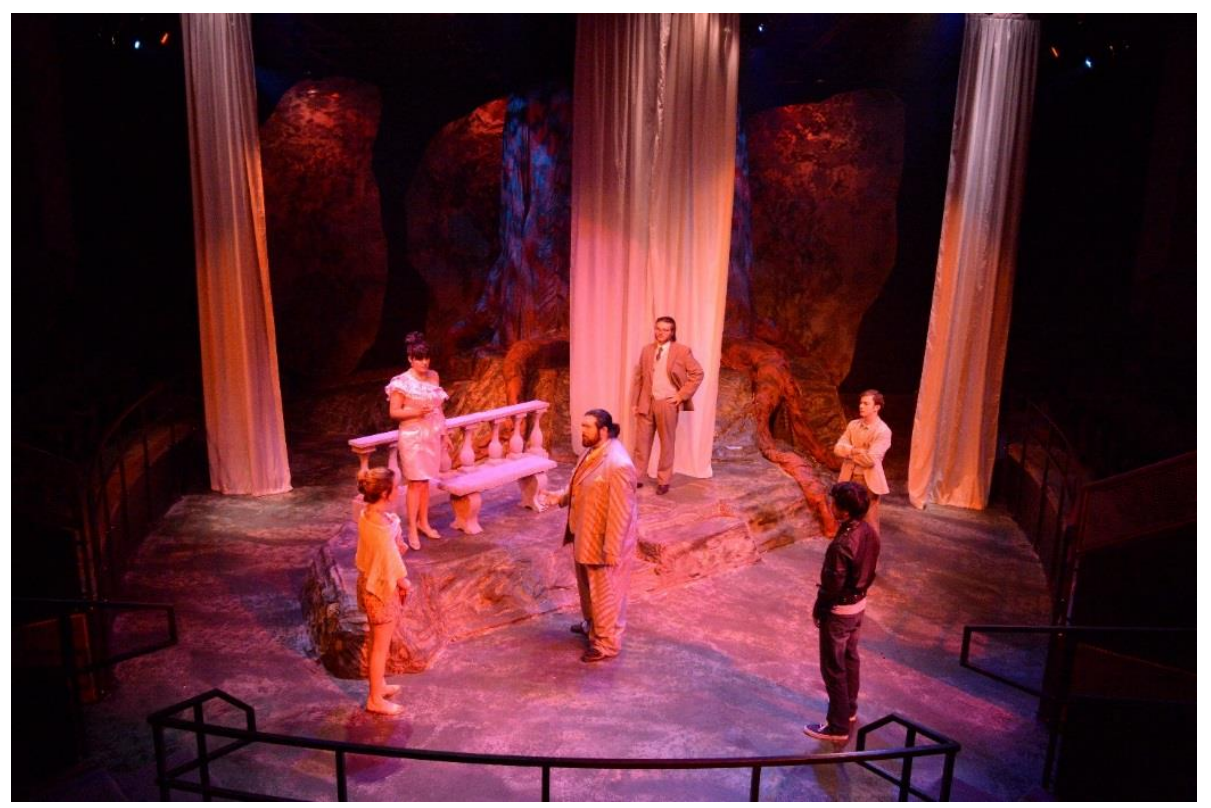

Act 2 Scene 1: Puck and Fairy meet

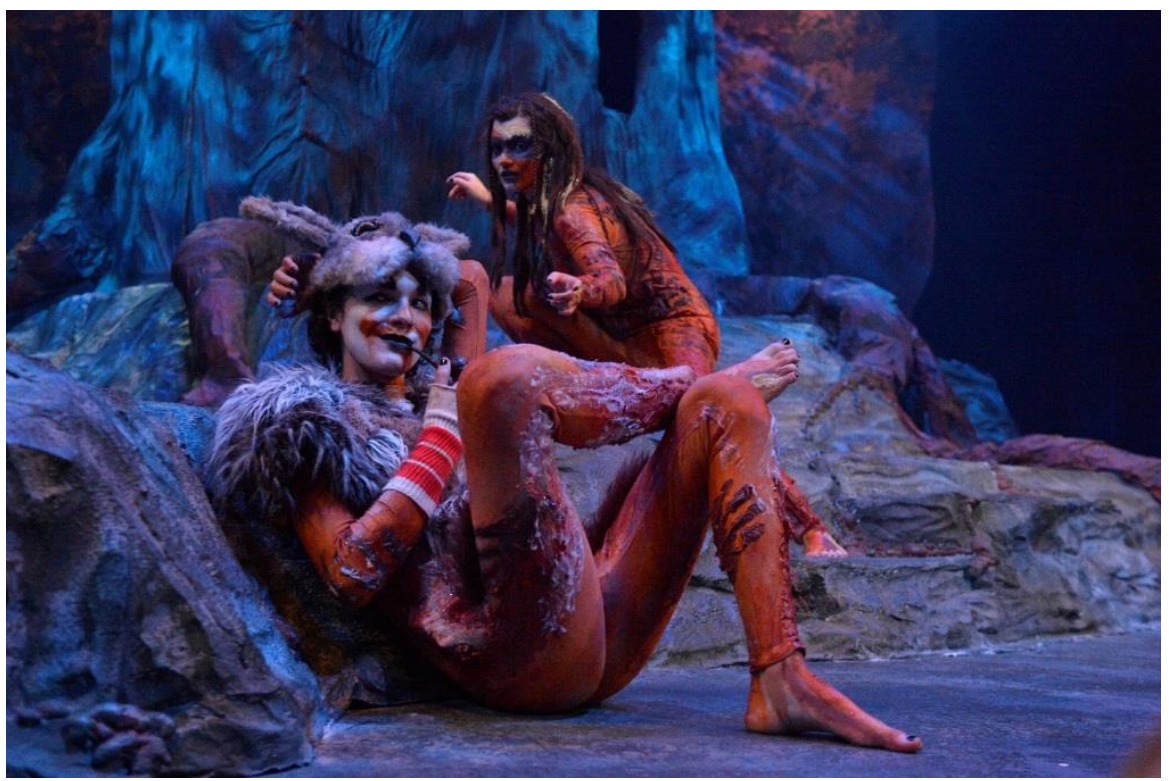


Act 2 Scene 1: Confrontation between Oberon and Titania

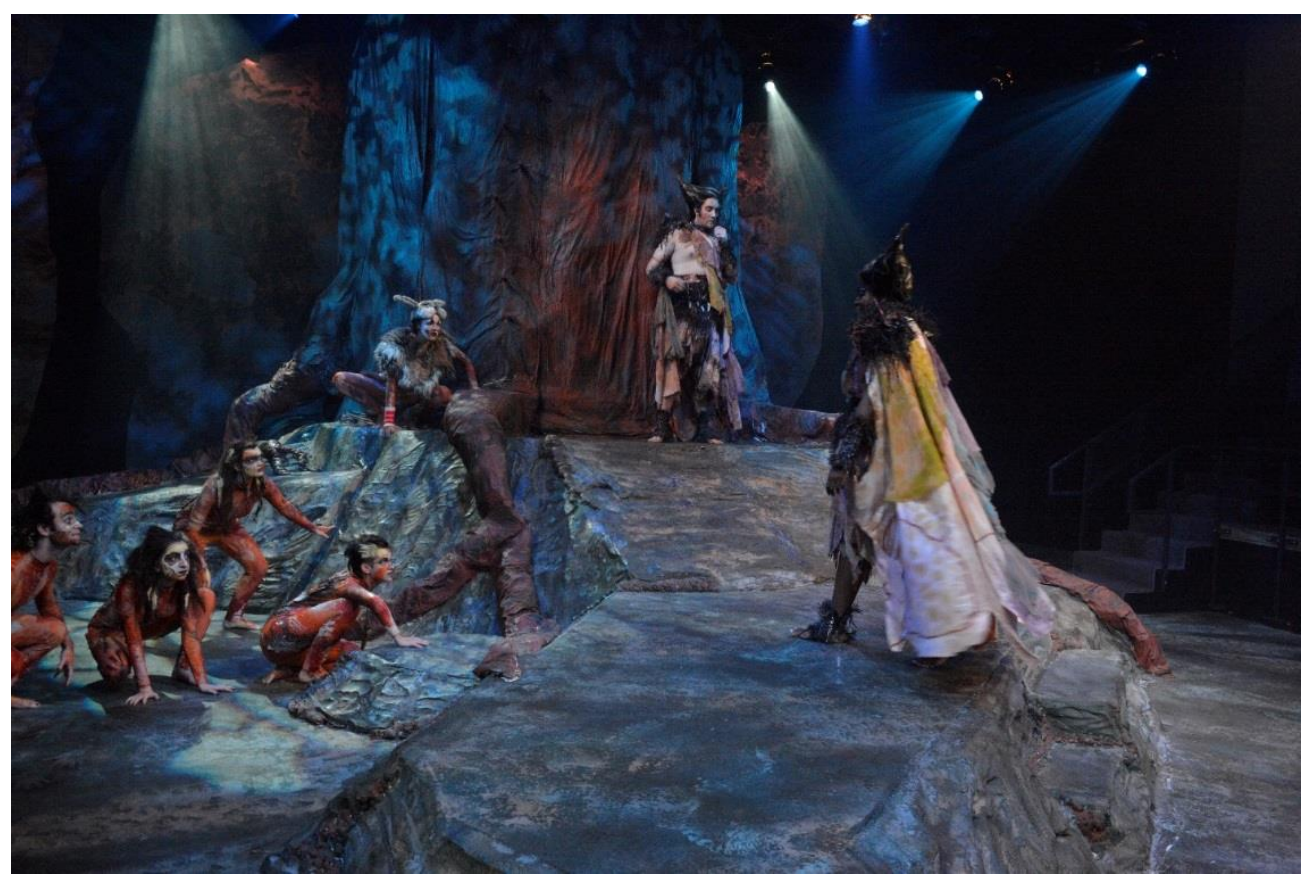

Act 2 Scene 2: Fairy Lullaby

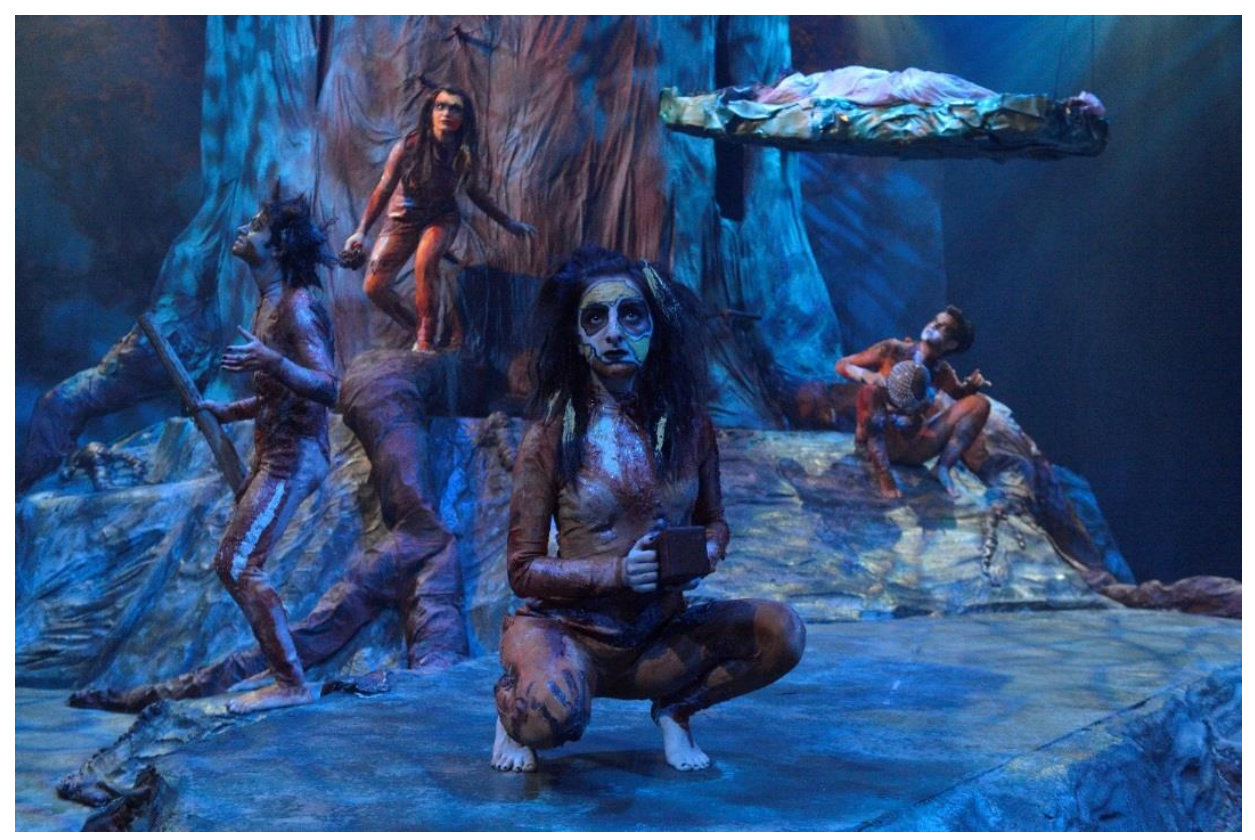


Act 3 Scene 1: Titania Falls in love with Bottom

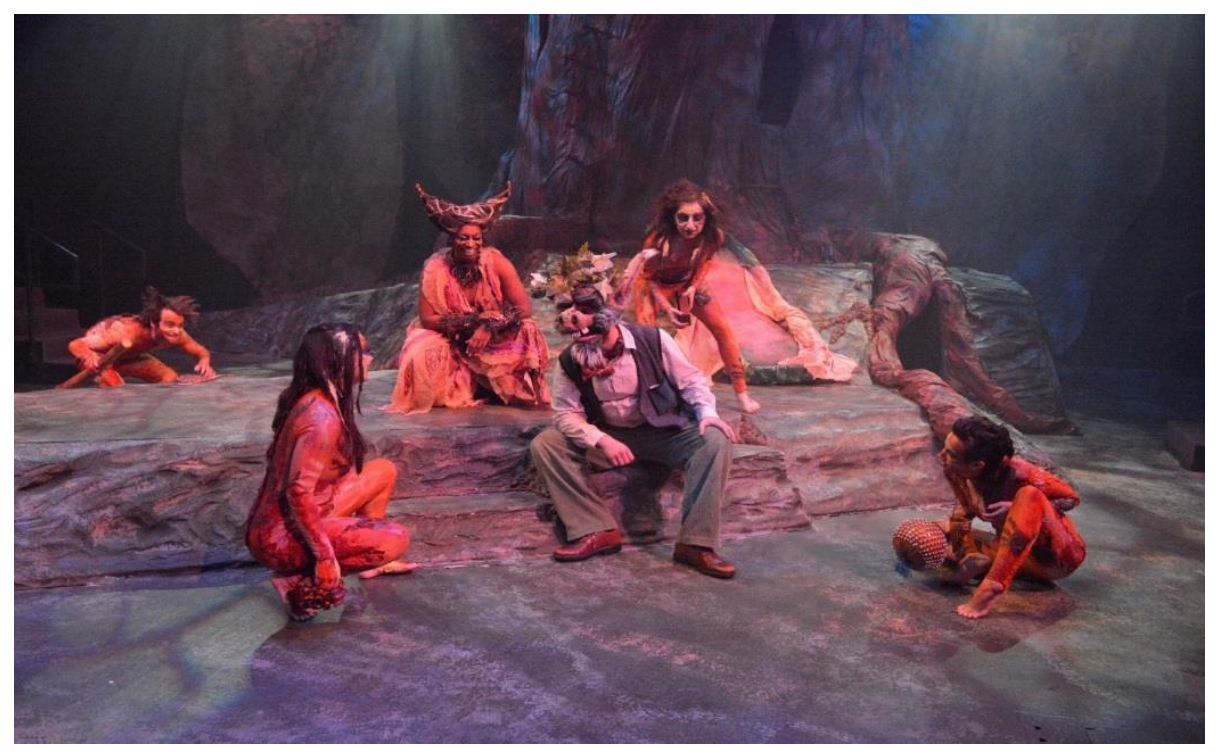

Act 3 Scene 2: The Lovers Duel

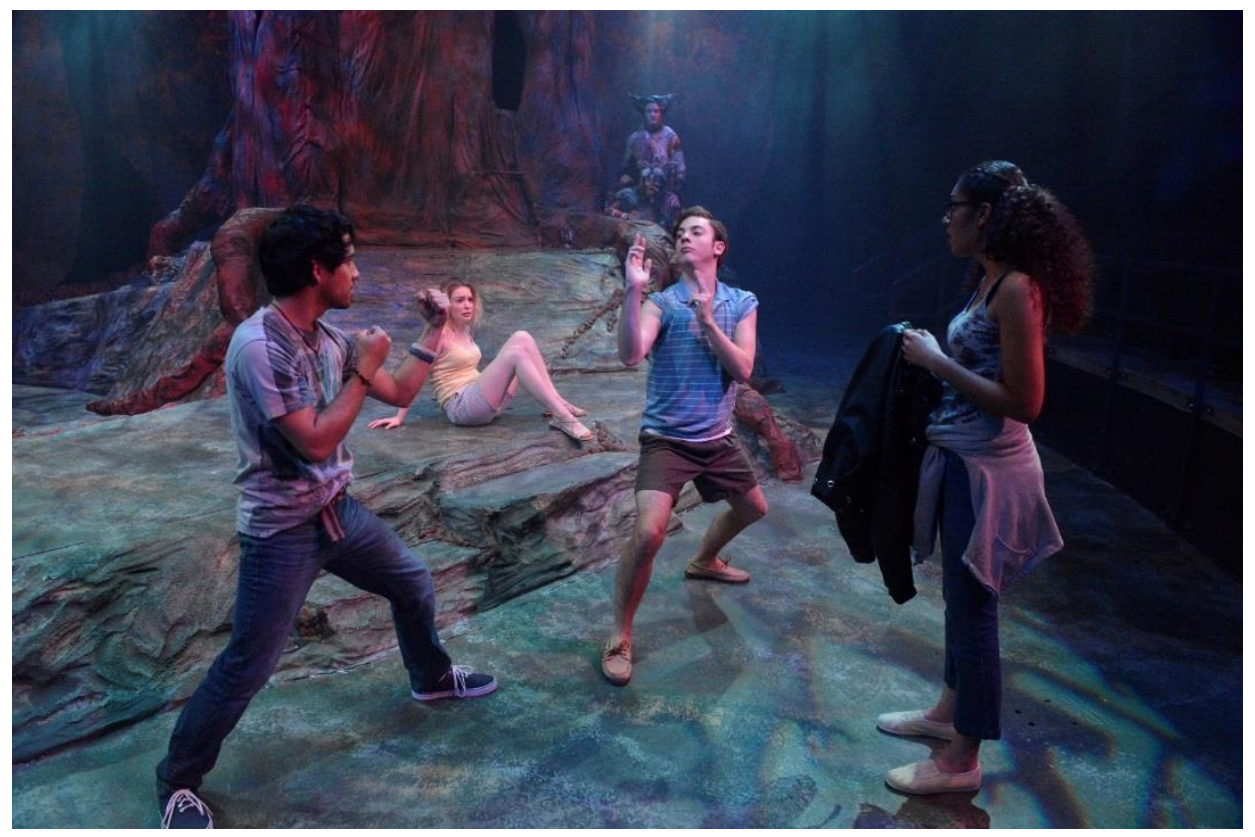


Act 4 Scene 1: The resolution of the Lovers Conflict

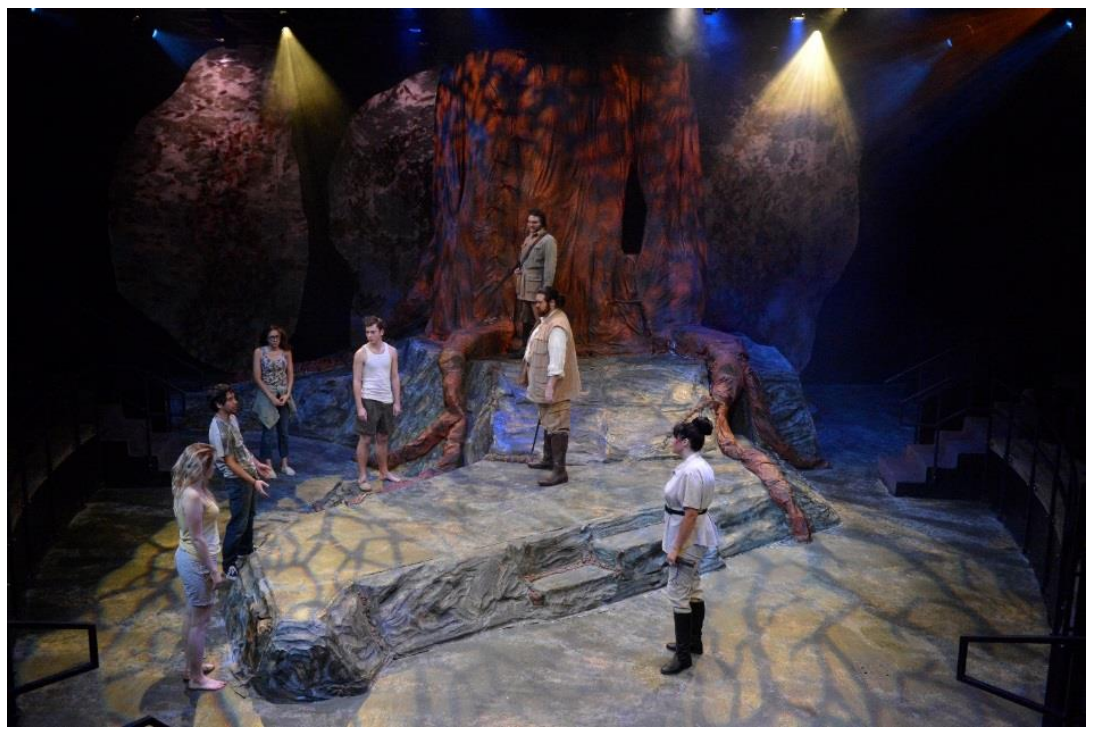

Act 5 Scene 1: The players preform

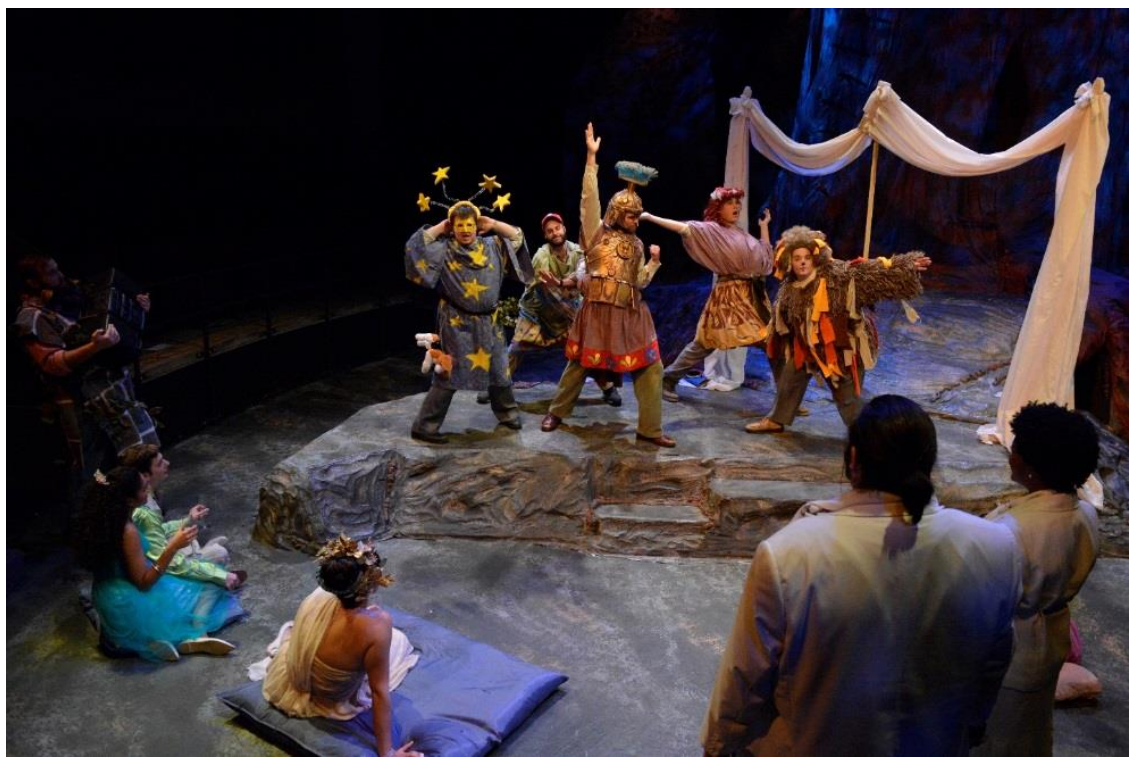


Act 5 Scene 1: Puck says farewell

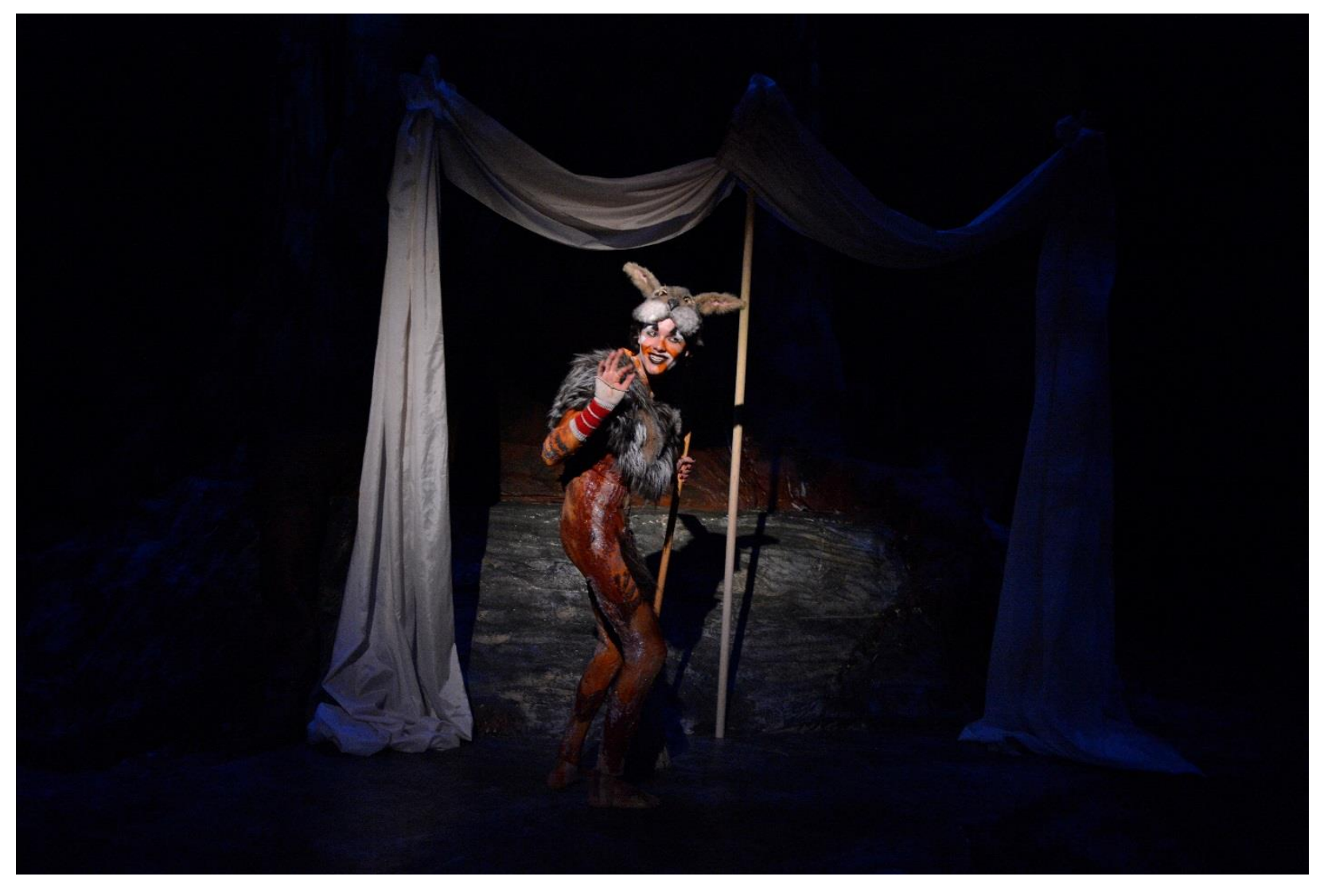


Bibliography

"All Costume Jewelry \& The Craft Works, a Great Place to Find Your Wedding and Bridal Party Accessories and Jewelry." All Costume Jewelry \& The Craft Works, a Great Place to Find Your Wedding and Bridal Party Accessories and Jewelry. N.p., n.d. Web. 23 July 2014.

<http://www.allcostumejewelry.com/art\%20nouveau\%2064\%20\%2810\%29.jpg>.

"The Best Photography Websites - Photo Hosting - Sell Photography." PhotoShelter. N.p., n.d.

Web. 22 Aug. 2014. <http://cdn.c.photoshelter.com/img-

get/I0000FvBnED7sTOE/s/860/860/JEAL0973-Ancient-Hands-Stencil-Paintings-RioPinturas-Canyon-Cave-of-t.jpg>. Hand Cave Painting

Goetz, Michelle. "Innovation - Vienna Secession." N.p., 22 Aug. 2011. Web. 21 July 2014. <https://michellegoetz.files.wordpress.com/2011/08/victorhortastaircase.jpg>.

"Hi I'm Dusky. Welcome to My World of Wonders." Duskys Wonders. N.p., n.d. Web. 22 Aug. 2014. <http://www.duskyswondersite.com/wp-content/uploads/2011/10/hans-s-5.jpg>. Omo Valley 1

Http://www.cotidianul.ro/. N.p., n.d. Web. 23 July 2014. <http://www.cotidianul.ro/images/curbele_voluptuoase_ale_femeilor_bantuie_art_nou veau.jpg>.

"Interesting Things, Humor, Facts, Videos, Wallpapers, plus Funny and Cool T Shirts." I Like To Waste My Time. N.p., n.d. Web. 7 Aug. 2014.

<http://iliketowastemytime.com/sites/default/files/nature_taking_over1.jpg>.

Reclaimed Car 
"The Maison Lavirotte." Feuilleton RSS. N.p., 19 Mar. 2008. Web. 21 Aug. 2014. <http://www.johncoulthart.com/feuilleton/2008/03/20/the-maison-lavirotte/>.

"Natural Fashions of the Omo Valley, Ethiopia." YouTube. YouTube, n.d. Web. 19 Aug. 2014. $\langle$ http://www.youtube.com/watch?v=RhG1KCW6S-k>.

N.p., n.d. Web. 21 Aug. 2014. <http://graphics8.nytimes.com/images/2013/06/20/garden/20NEST_SPAN/20NEST1articleLarge.jpg>. Human Nest

N.p., n.d. Web. 22 Aug. 2014. <http://media.tumblr.com/tumblr_lw73rh6SfP1qc3j1s.jpg>. Omo Valley Woman

N.p., n.d. Web. 23 July 2014. <http://1.bp.blogspot.com/_65TLvveXmmg/TDSBXnfI_sI/AAAAAAAABSM/EcnzIe oyo6M/s1600/IMG_9502.JPG>. Angkor Wat \#1

N.p., n.d. Web. 23 July 2014. <https://c1.staticflickr.com/3/2191/2327094938_c1cfe2ab2e.jpg>. Grasping Tree

N.p., n.d. Web. 7 Aug. 2014. <https://c2.staticflickr.com/2/1092/5156483396_0888f1ea7e_z.jpg>. Angkor Wat \#2 Image

Shakespeare, William. A Midsummer Night's Dream. Ed. Stanley Wells. Harmondsworth: Penguin, 1967. Print.

"Steve'sDigicams." Steves Digicams Forums RSS. N.p., n.d. Web. 28 Aug. 2014. $<$ http://forums.steves-digicams.com/attachments/panasonicleica/180336d1313232287-strange-creatures-greek-forests-p1010649b.jpg>. Tree Ideas 